\title{
Static Resistance Function for Steel-Plate Composite (SC) Walls Subject to
}

\section{Impactive Loading}

\author{
Jakob C. Bruhl, PhD, PE ${ }^{a, *}$ Amit H. Varma, PhD ${ }^{a}$, Joo Min Kim, PE ${ }^{a}$ \\ ${ }^{a}$ Lyles School of Civil Engineering, Purdue University, 500 Stadium Mall Drive, West \\ Lafayette, IN 47907-2051
}

\begin{abstract}
Steel-plate composite (SC) walls consist of a plain concrete core reinforced with two steel faceplates on the surfaces. Modules (consisting of steel faceplates, shear connectors and tie-bars) can be shop-fabricated and shipped to the site for erection and concrete casting, which expedites construction schedule and thus economy. SC structures have recently been used in nuclear power plant designs and are being considered for the next generation of small modular reactors. Design for impactive and impulsive loading is an important consideration for SC walls in safety-related nuclear facilities. The authors have previously developed design methods to prevent local failure (perforation) of SC walls due to missile impact. This paper presents the development of static resistance functions for use in single-degree-of-freedom (SDOF) analyses to predict the maximum displacement response of $\mathrm{SC}$ walls subjected to missile impact and designed to resist local failure (perforation). The static resistance function for SC walls is developed using results of numerical analyses and parametric studies conducted using benchmarked 3D finite element (FE) models. The influence of various design parameters are discussed and used to develop idealized bilinear resistance functions for SC walls with fixed edges and simply supported edges. Results from dynamic non-linear FE analysis of SC panels subjected to rigid missile impact are compared with the maximum displacements predicted by SDOF analyses using the bilinear resistance function.
\end{abstract}


Keywords: projectile impact, composite structure, concrete, steel plate

\section{*Corresponding author}

Email address: jbruhl@purdue.edu (Jakob C. Bruhl, PE) 


\section{Introduction}

Steel-plate composite (SC) walls consist of two exterior (surface) steel faceplates with plain concrete infill as shown in Figure 1. The steel faceplates are anchored to the concrete core using steel headed stud anchors that are welded to the interior surfaces of the steel faceplates and cast in concrete. The steel faceplates are connected to each other using tie systems that are also cast in concrete. Composite action between the steel faceplates and concrete core is provided by the stud anchors and the tie systems. The tie systems provide: (a) structural integrity to the SC wall by resisting splitting through the plain concrete core, (b) out-of-plane shear reinforcement, and (c) stability to the empty steel modules during transportation and erection. The stud anchors provide: (a) restraint for local buckling of steel faceplates, and (b) interfacial shear resistance.

As shown in Figure 1, the concrete infill is contained between the steel faceplates. Shop fabrication of steel modules, consisting of the steel faceplates, tie systems and stud anchors, is possible because no reinforcing bar cages are required in SC walls. The steel faceplates serve as primary reinforcement and formwork for casting concrete. No additional work is required to construct or remove formwork. Due to these efficiencies, SC structures can be constructed in approximately half the time required for similar conventional reinforced concrete (RC) structures [1]. SC walls have recently been used as primary and secondary shield walls in nuclear power plants (NPP) [2,3].

The analysis and design of safety-related nuclear facilities consisting of SC walls is governed by Appendix N9 of AISC N690s1-15 [4]. This specification is built upon experimental and numerical research conducted by Varma et al. [5], Zhang et al. [6], Sener et al. [7,8], Seo et al. [9], Bharadwaj et al. [10] and Bruhl et al. [11]. For example, the design of stud anchors and its influence on the level of composite action and local buckling of the steel faceplates is 
discussed in [6]. The out-of-plane shear behavior and design of SC walls is discussed in [8], and the behavior and design for out-of-plane flexure is discussed in [7]. The behavior and design of SC walls for in-plane shear is discussed in [9], and the behavior and design of SC walls for combined in-plane membrane force and out-of-plane moments is discussed in [5]. The specification also provides minimum requirements and section detailing provisions for each component (steel faceplate, stud anchors, tie systems, and concrete infill) of the SC wall [10].

\section{Background}

SC walls in safety-related nuclear facilities have to be designed for impactive and impulsive loading [12]. Previous research has demonstrated the effectiveness of SC walls in resisting local damage (scabbing, penetration and perforation) due to missile impact. Mizuno et al. [13] concluded that an SC wall provides the same level of protection (preventing wall perforation) as an RC wall that is approximately $30 \%$ thicker. Several researchers have suggested that the steel faceplate can be considered to provide an equivalent thickness of concrete, and the total equivalent concrete thickness may be used with $\mathrm{RC}$ wall equations to evaluate impact performance [14-16].

The authors have recently developed and verified a three-step approach for designing SC walls to prevent local perforation due to missile impact [11]. The method can be used to compute the minimum required steel faceplate thickness to prevent local perforation. The method was verified using a comprehensive experimental database of over 100 missile impact tests. The authors also presented the development and benchmarking of $3 \mathrm{D}$ finite element models for predicting the behavior and local failure of SC walls subjected to missile impact [11]. These models were benchmarked using results from the experimental database, and the results were 
used to confirm the failure mechanism of SC walls subjected to missile impact. The benchmarked models were used to conduct analytical parametric studies to expand the database, and further verify the design method. This previous research does not consider the structural response or the maximum deflection of the SC wall subjected to missile impact. Consequently, the designed SC wall may prevent local perforation, but not satisfy other design criteria such as maximum deflection limits.

SC walls should also be designed to satisfy global design criteria such as flexure, shear, rotation or deflection limits. However, there is limited literature available on the global impact or two-way behavior of SC walls or slabs. Sohel and Liew $[17,18]$ evaluated the structural performance (local and global behavior) of a unique configuration of SC slabs consisting of steel faceplates anchored to the concrete core using j-hooks serving as both stud anchors and tie systems. They experimentally evaluated the static resistance of simply supported two-way slabs subjected to central patch loading [17]. The parameters included were the thickness of the concrete core, thickness of the steel faceplates, and the type of concrete (lightweight or fiber reinforced). The authors concluded that the behavior of SC slabs was similar to that of RC slabs. The observed yield line mechanism and load-deflection curves were similar to those of two-way, simply supported, RC slabs. Possible failure modes included punching shear failure, shear connector failure, buckling and yielding of steel faceplates. When punching shear failure and shear connector failure modes were prevented, the load-deflection response was elastic-perfectly plastic until large deflections and membrane action provided additional increase in strength. Deflection ductility values were approximately 10 and 15 for SC slabs with normal weight and lightweight concrete cores, respectively.

Results from experimental investigation of the structural performance of SC slabs with j- 
hooks subjected to impact loading was presented in [18]. The parameters included were the concrete core thickness, steel faceplate thickness, and type of concrete (lightweight or fiber reinforced). The SC slabs were subjected to impact using a 2700-lb mass with hemispherical projectile head guided (dropped) from a height of 9.9-ft resulting in impact velocities of $22-24$ $\mathrm{ft} / \mathrm{sec}$. The experimental results included the local indentation and the deformation profile of the SC slabs at both the top and bottom steel faceplates, along with the impact force-time history. Sohel and Liew developed an energy balance method to estimate the maximum deflection and impact force. An idealized form of the static resistance (load-deflection) function measured in their previous study [17] was used as input in the energy balance calculation. The analytical results underestimated maximum mid-span displacement by up to $22 \%$, and impact force by up to $25 \%$.

\section{Approach}

This paper implements the single-degree-of freedom (SDOF) method to characterize and evaluate the displacement response of SC panels subjected to impactive loading, which is similar to the method used to evaluate the displacement response of RC panels subjected to missile impact. The SDOF method is used because of the similarities between the out-of-plane shear behavior [8] and flexural behavior [7] of SC and RC walls. This SDOF method is used conventionally to evaluate the response of RC panels to impactive and impulsive loads and is well known in the research and engineering practice communities [19-21]. The SDOF method characterizes the structural (total) displacement of RC panels including the development of a collapse mechanism and deformation through rotation of plastic hinges and is used when the panel can prevent local failure modes (perforation) due to impact. 


\section{SDOF Method for RC panels}

The SDOF method consists of solving Equation 1, which is the equation of motion for dynamic equilibrium. In this equation, $M_{e}$ is the effective mass of the structure, $C$ is the effective structural damping, $R(y)$ is the static resistance as a function of the displacement $y(t), F(t)$ is the applied forcing function, $\dot{y}(t)$ is the first derivative of displacement with respect to time (velocity), and $\ddot{y}(t)$ is the second derivative of displacement with respect to time (acceleration). The peak displacement response due to impactive or impulsive loading occurs in the first cycle, and structural damping, $C$, does not have a significant influence on its value. As a result, structural damping is typically not included [21], and Equation 2 becomes the most commonly used form of the equation of motion used to calculate the peak displacement due to missile impact.

$$
\begin{gathered}
M_{e} \cdot \ddot{y}(t)+C \cdot \dot{y}(t)+R(y) \cdot y(t)=F(t) \\
M_{e} \cdot \ddot{y}(t)+R(y) \cdot y(t)=F(t)
\end{gathered}
$$

As shown in Figure 2(a), the static load-displacement behavior of RC panels exhibits elastic-plastic behavior followed by hardening due to tensile membrane action. However, the effects of tensile membrane action are typically ignored, and the resistance function, $R(y)$, is assumed to be elastic-perfectly plastic as shown in Figure 2(b). The critical parameters defining this idealized resistance function are the maximum resistance, $R_{m}$, and the elastic deflection, $X_{E}$. Equations to calculate these parameters $\left(R_{m}\right.$ and $\left.X_{E}\right)$ are available in a variety of sources [19-21]. The effective mass, $M_{e}$, for the SDOF model is calculated by multiplying the total mass of the panel $\left(M_{t}\right)$ by a transformation factor, $K_{M}$, which is based on member geometry, support 
conditions, and the expected response (elastic, elasto-plastic, or plastic). Values of the mass transformation factor, $K_{M}$, for the case of uniform loading acting on two-way RC slabs are available in the literature, typically in the same sources that include equations for $R_{m}$ and $X_{E}$. However, values of $K_{M}$ for the case of central concentrated load acting on two-way slabs with different support conditions are not provided in the literature. $K_{M}$ can be calculated using Equations $3-6$, where Equation 4 is for the effective mass $\left(M_{e}\right)$ and includes the displacement shape function $[\Phi(x, y)]$.

$$
\begin{aligned}
& K_{M}=\frac{M_{e}}{M_{t}} \\
& M_{e}=\iint[m \Phi(x, y)]^{2} d x d y \\
& M_{t}=\iint m(x, y) d x d y \\
& K_{M}=\iint[\Phi(x, y)]^{2} d x d y
\end{aligned}
$$

The forcing function, $F(t)$, in Equation 2 can be developed using the Riera method, which converts the momentum of the impacting object into a reaction force for a rigid structure and can account for obliquity (angle) of impact [22]. Other acceptable methods for developing forcing functions for missile impact are provided in [20]. For certain beyond-design-basis cases, the U.S. Nuclear Regulatory Commission (NRC) provides the forcing function, which is considered safeguards information and is not available in the public domain [23]. For simplified forcing functions (such as rectangular or triangular pulses) and assumed resistance functions (elastic or elasto-plastic), solutions for peak displacement are available in the literature [21]. The peak displacement values can be used to estimate the required displacement ductility and rotation capacity for panel structures subjected to missile impact. For RC panels, the available ductility (and required rotation capacity) are provided in ACI 349 App. F [24]. The global resistance and 
performance of RC panels to impactive loading can be evaluated by comparing the required and available displacements.

\section{SDOF Method for SC Panels}

Implementing the SDOF method for SC panels involved solving the equation of motion (Equation 2) to determine the maximum displacement for impactive loading. The two parameters required to completely define the model were the effective mass, $M_{e}$, and the resistance function, $R(y)$. This paper presents the development of the resistance function, $R(y)$, followed by the calculation of the effective mass, $M_{e}$, and mass transformation factor, $K_{M}$.

The effective mass, $M_{e}$, of the SDOF model was calculated using the displacement shape function $[\Phi(x, y)]$ corresponding to the collapse mechanism of the panel structure. Preliminary analysis by the authors [25] indicated that the collapse mechanism for SC panels with fixed edges was similar to the mechanism for RC panels, i.e., with radial crack pattern and yield lines as shown in Figure 3(a). Prior research by Sohel and Liew [17] has shown that the collapse mechanism for SC panels with simply supported edges consisted of diagonal crack pattern and yield lines, as shown in Figure 3(b). These potential collapse mechanisms for different boundary conditions were used as the displacement shape function $[\Phi(x, y)]$ to calculate the mass transformation factor, $K_{M}$, and the effective mass, $M_{e}$, for the SDOF model. These calculations are presented later in the paper after verifying the assumed collapse mechanisms using numerical models.

The static resistance function was developed using numerical (3D finite element) models of the SC panels. These 3D finite element models were similar to those developed earlier for the 
local missile perforation studies, and were benchmarked using large-scale experimental results. Detailed parametric studies were conducted using the benchmarked models to investigate the influence of numerous parameters including the SC panel thickness, span-to-panel thickness ratio, concrete compressive strength, steel faceplate yield strength, reinforcement ratio, faceplate slenderness ratio, tie spacing-to-panel thickness ratio, and boundary conditions. The results from detailed parametric studies indicated that the static resistance function for an SC panel could be idealized as a bilinear curve with post-yield strain hardening, and the two anchor points for the bilinear curve could be defined using the results from the detailed parametric studies. These anchor points were modified to account for strain rate effects, and the resulting bilinear resistance function with strain hardening, $R(y)$, was used to define and solve the equation of motion for the SDOF model for SC panels. The bilinear nature of the resistance function

prohibited the use of response charts for determination of peak displacement response and required ductility. However, the equation of motion could be solved using one of several numerical methods such as finite difference recursion relation, constant acceleration, linear acceleration, or Newmark's method $[19,26]$.

\section{Static Resistance of SC Panels: Numerical Models and Benchmarking}

The SC panels considered in this study were flat square plates, as shown in Figure 4. The structural details of the SC panels considered in this study satisfy the requirements of Appendix N9 of AISC N690s1-15 [4]. These SC panels are representative of typical exterior and interior walls of safety-related nuclear facilities. The finite element analyses were conducted using LSDYNA Version 971, Release 5.1.1. [27]. 
Numerical Model: 3D Finite Element Method (FEM)

The authors have previously developed and benchmarked numerical (3D FEM) models for predicting the local failure (scabbing, penetration and perforation) of SC panels subjected to missile impact [11]. The 3D FEM models used in this paper for investigating the structural behavior of SC panels were based on the previously benchmarked models for local failure with three exceptions. First, the finite element mesh for the original model was small (fine) to focus on local perforation behavior. The finite element mesh size for the present study was larger (coarse) to focus on the structural displacement behavior of SC panels, which were considerably larger (in span length) than those modeled to evaluate local perforation behavior. Second, the original finite element model focused on modeling local damage (scabbing, penetration, and perforation), and included erosion criteria for the concrete elements. The present study does not include erosion criteria for concrete elements because it focuses on the structural response of SC panels that do not undergo local failure (perforation) due to missile impact. Third, the original finite element model was developed for dynamic analysis associated with rigid missile impact, and it included strain rate effects on material strength. The present study focused on the static resistance of SC panels, and therefore, strain rate effects on material strength were not included. This resulted in a slight change in defining the input parameters for the tension behavior of the Winfrith (MAT_084/085) concrete material model in LS-DYNA. When strain rate effects are not included, this concrete model assumes a linearly softening tension stress-crack opening displacement $(\sigma-u)$ response. The input parameters are the concrete tensile stress capacity $\left(f_{t}\right)$ and the crack opening $\left(u_{o}\right)$ corresponding to zero tensile stress. The resulting (specified) material fracture energy $\left(G_{f}\right)$ is equal to the area under the $(\sigma-u)$ curve, and can be calculated as $\left(1 / 2 \times f_{t} \times\right.$ $u_{o}$ ). 
Figure 5 shows the typical 3D FEM models for SC panels. As shown, the concrete infill (core) is modeled using multiple layers of solid brick elements with reduced integration (SOLID ELFORM 1). The steel faceplates are modeled using single layer of solid brick element with full integration for poor aspect ratios (SOLID EFLORM -1). The tie bars and stud anchors were modeled using Hughes-Liu beams elements with cross-section integration (BEAM ELFORM 1). The interfacial slip resistance between the steel faceplates and concrete infill is modeled using discrete beam connector elements (BEAM ELFORM 6). As explained in [6] and [11], these connector elements model the interfacial shear force-slip resistance provided by the stud anchors and tie bars.

Table 1 provides all the material properties used for the 3D FEM models. It includes the material properties for the concrete elements (MAT_084/085), namely, the mass density, elastic modulus, Poisson's ratio, uniaxial compressive strength, uniaxial tensile strength, fracture energy, and crack width at zero tensile strength. The table also includes all the material properties for the steel elements (steel faceplates, tie bars, and stud anchors), namely, the mass density, elastic modulus, Poisson's ratio, and plastic strain at erosion. Table 1 also provides the material properties for the connector elements including the displacement at failure and the reference for the specified force-slip relationship. The table also includes the material properties for the supports and loading plates, and the constraints applied to global degrees of freedom associated with translation or rotation.

Two support conditions (fixed and simply supported) were considered for the parametric studies. These support conditions were implemented by restraining the appropriate translation and rotation degrees of freedom for the nodes along the supported edges. The SC panels were subjected to concentrated loading at the center, which caused bending behavior with two axes of 
symmetry. This symmetry was leveraged to achieve computational efficiency by modeling only a quarter portion of the SC panel with appropriate symmetry boundary conditions.

The concentrated loading was applied as a monotonically increasing pressure on a circular region at the center of the SC panel. This pressure was applied using the keyword LOAD SEGMENT SET. The area over which the pressure was spread, i.e., the diameter of the circular region had to be small enough to represent the effects of concentrated loading or missile impact, but not so small as to cause local (punching shear) failure. As mentioned earlier, this study focuses on the structural response of SC panels that do not undergo local failure (perforation etc.) due to missile impact. The authors conducted preliminary investigations to evaluate the influence of size of the loaded area on the maximum moments for simply supported and fixed end beams [25]. Based on these investigations, the diameter of the circular (loaded) region was selected to be one-fourth of the SC panel span. As compared to the moments due to pure concentrated forces, this distribution reduced the maximum midspan moment for simply supported beams by $12.5 \%$, and the maximum midspan and end moments for fixed end beams by $23 \%$ and $2.1 \%$, respectively. It also reduced the chances for local (punching shear) failure of the SC panels, which was in accordance with the goal (global response of SC panels) of the study.

\section{Verification of 3D FEM model}

Experimental results from ten static beam tests conducted in the US by Sener et al. [8] and the authors were used to verify the 3D FEM models. Table 2 summarizes the details of these static beam tests. It includes the various geometric, material, and loading parameters of these tested specimens, namely, the beam depth or panel thickness $\left(t_{s c}\right)$, simply supported span lengthto-beam depth $\left(L / t_{s c}\right)$, beam width-to-depth ratio $\left(b_{w} / t_{s c}\right)$, steel faceplate thickness $\left(t_{p}\right)$, 
reinforcement ratio $\left(\rho=2 t_{p} / t_{s c}\right)$, the shear span-to-depth ratio $\left(a / t_{s c}\right)$, stud anchor diameter to faceplate thickness ratio $\left(d_{s t u d} / t_{p}\right)$, stud anchor spacing-to-faceplate thickness ratio $\left(s / t_{p}\right)$, tie bar reinforcement ratio $\left(\rho_{t}\right)$, tie bar spacing-to-beam depth ratio $\left(S / t_{s c}\right)$, concrete compressive strength $\left(f_{c}^{\prime}\right)$, faceplate yield strength $\left(f_{y}\right)$, and loading type (three- or four-point bending). The Table also includes the observed failure mode from the test (shear failure SF, interfacial shear failure ISF or flexural failure FF). The tie bar reinforcement ratio $\left(\rho_{t}\right)$ is calculated as the ratio of the area of the tie bar $\left(A_{t i e}\right)$ to the square of the tie spacing $\left(S^{2}\right)$. The Table also includes the $M_{n} / \mathrm{V}_{\mathrm{n}} t_{s c}$ ratio calculated for the specimens, where $M_{n}$ and $V_{n}$ are the flexural capacity and out-of-plane shear strengths of the specimens calculated using AISC N690s1-15 design equations and measured material properties. When the shear span-to-depth $\left(a / t_{s c}\right)$ ratio is larger than the $M_{n} / V_{n} t_{s c}$ ratio, flexural failure (FF) was expected; otherwise, shear failure (SF) was expected.

As shown in Table 2, four of the seven beam specimens tested by Sener et al [8] were subjected to three-point bending, and the remaining were subjected to four-point bending. Five of the seven beam specimens had shear failure mode (SP1-1, SP1-3, SP1-4, SPa-1and SP2a-3), one specimen (SP1-2) had interfacial shear failure mode, and one specimen (SP2a-4) had flexural failure mode. Specimen SP1-2 had interfacial shear failure because of inadequate stud anchors along the length, which is evident from the largest $s / t_{p}$ ratio of 36 in Table 2 . Sener et al. [8] had designed this specimen (SP1-2) with $s / t_{p}$ ratio greater than that permitted by AISC N690s1-15 to illustrate the interfacial shear failure mode. All three specimens tested by the authors listed in Table 2 were small-scale $\left(t_{s c}=4\right.$ in.), subjected to four-point bending using the experimental procedure described in [28], and had flexural failure mode.

The details of the 3D FEM models developed for these beam specimens were identical to those described earlier in this section. Rigid solid parts were used in the FEM models to apply 
the loading and support the beam specimens. The appropriate degrees of freedom of these rigid parts were restrained depending on their location (load plates or support). These rigid solid parts were modeled using a rigid material model (MAT 020) with input parameter values listed in Table 1.

Figure 6 shows comparisons of the shear force-midspan displacement curves predicted by the 3D FEM models with those measured experimentally for Specimens SP1-3, SP2a-3, SP2a-4 and S-1-A. The comparisons shown in Figure 6 are similar and representative of the comparisons for the remaining specimens included in Table 2. Specimens SP1-3 and SP2a-3 had shear failure mode, and Specimens SP2a-4 and S-1-A had flexural failure mode. The 3D FEM models predict the force-displacement behavior including initial stiffness, softening, and maximum capacity of specimens with different failure modes (shear failure, interfacial shear failure or flexural failure) with reasonable accuracy. Numerical comparisons of the maximum force capacity of the specimens $\left(V_{n}^{\text {test }}\right)$ with those predicted by the 3D FEM models $\left(V_{n}{ }^{F E M}\right)$ are included in Table 2. Additionally, the table also includes numerical comparisons of the secant stiffness of the specimens $\left(K_{\text {test }}\right)$ corresponding to $0.67 V_{n}^{\text {test }}$ with the secant stiffness $\left(K_{F E M}\right)$ predicted by the FEM models at $0.67 V_{n}{ }^{F E M}$. The average value of $V_{n}{ }^{\text {test }} / V_{n}{ }^{F E M}$ is equal to 0.99 , and the coefficient of variation is equal to 0.12 . The average value of $K_{\text {test }} / K_{F E M}$ is equal to 0.89 and the coefficient of variation is equal to 0.19 . The FEM models were generally conservative for specimens with flexural failure. The ultimate displacements at failure predicted by the FEM models were conservative with respect to the experimental results because the models used steel failure (erosion) strain of 0.05 (shown in Table 1), which is conservative with respect to steel faceplate material properties for the tests. 


\section{Static Resistance Function: Parametric Studies}

The verified 3D FEM models were used to conduct parametric studies and evaluate the influence of various design parameters on the behavior of SC panels. The SC panel details and the range of parameters used for these investigations were in accordance with the requirements of AISC N690s1-15. Table 3 summarizes all the geometric and material details of the 27 SC panel designs used to conduct the analytical parametric studies. The parameters considered and the ranges of values were as follows: (i) wall thickness, $t_{s c}$, from 12 to 48 inches, (ii) span-to-wall thickness ratio, $L / t_{s c}$, from 3 to 15 , (iii) concrete compressive strength, $f_{c}^{\prime}$, from 4 to $6 \mathrm{ksi}$, (iv) steel faceplate yield strength, $F_{y}$, from 50 to $65 \mathrm{ksi}$, (v) reinforcement ratio, $\rho$, from 2.0 to $5.0 \%$, (vi) slenderness ratio, $s / t_{p}$, from 10 to 20 , and (vii) tie spacing-to-wall thickness ratio, $S / t_{s c}$, from 0.5 to 1.5 . Two different boundary conditions (fixed $F$, or pinned $P$ ) were also considered. The length of stud anchors for all SC panels was 8 times $d_{\text {stud }}$, which exceeds the height-to-diameter requirements specified by AISC N690s1.

The nomenclature used to identify SC panels in Table 3 and the rest of the paper consists of all seven parameters in order. For example, Specimen F-36-8-4.2-12-0.5-5-50 has fixed boundary conditions with $t_{s c}$ equal to 36 in., $L / t_{s c}$ ratio equal to $8, \rho$ equal to $4.2 \%, s / t_{p}$ ratio of 12 , $S / t_{s c}$ ratio of $0.5, f_{c}^{\prime}$ of $5 \mathrm{ksi}$, and $F_{y}$ of $50 \mathrm{ksi}$. The models are grouped together in sets in Table 3 , and the parameter being varied (while all other parameters remain constant) is highlighted using bold letters. Table 3 also includes the flexural capacity $\left(M_{n}\right)$ and the cracked transformed effective flexural stiffness ( $E I_{\text {eff }}$ calculated for all the models using AISC N690s1 recommendations). While the $M_{n} / V_{n} t_{s c}$ ratio is a useful parameter for beams, it is not meaningful for two-way bending and is therefore not listed in Table 3 for the panels as it is in Table 2 for the beams. 
All 27 SC panels were analyzed for monotonically increasing concentrated loading, which was spread over a central region with diameter equal to span length divided by four. The analytical results included the concentrated force-midspan displacement $(P-\Delta)$ responses, the stresses and strains in all the finite elements, and the forces in the connector elements. The flexural behavior of the SC panels is discussed first, followed by the idealized static resistance function, and finally the influence of the specific parameters.

\section{Flexural Behavior of SC Panels}

Figure 7 shows the representative $P-\Delta$ responses for SC panels with fixed and pinned support conditions. The figure also identifies the occurrence of major events along the $P-\Delta$ responses, namely: $(A)$ diagonal shear cracking in concrete, $(B)$ tension steel plate yielding, and (C) tension steel plate rupture. The $P$ - $\Delta$ responses followed elastic bending theory up to event $(A)$, and the initial stiffness could be predicted using tabulated equations for bending of elastic plates with uniform thickness, flexural stiffness equal to $E I_{\text {eff, }}$ straight boundaries, and appropriate boundary conditions in [29]. Elastic behavior theory was not appropriate for $P$ - $\Delta$ responses between events $(A)$ and $(B)$ because diagonal shear cracks developed around the circular loaded region, and propagated through the depth of the concrete infill forming a conical frustum under the loaded area. This concrete conical frustum caused localized deformation under the loaded area, which could not be accounted by elastic bending theory using $E I_{\text {eff }}$ alone. These localized deformations increased stresses in the tension faceplate under the loaded area, and further reduced the stiffness of the $P$ - $\Delta$ response after yielding (event $B$ ). Yielding initiated at the center 
of the tension faceplate, spread radially toward the panel edges for fixed supports, and spread diagonally toward the corners for panels with simple supports.

Yielding of the compression faceplate initiated after yielding of the tension faceplate had spread to approximately the size of the loaded area. Compression faceplate yielding initiated around the circumference of the loaded area and spread radially as load increased. Failure of the SC panel occurred when the tension faceplate ruptured. The collapse mechanism for panels with fixed edges had radial yield lines and crack pattern as shown in Figure 3(a). The collapse mechanism for panels with simply supported edges had diagonal yield lines and crack pattern as shown in Figure 3(b). The plastic loads $\left(P_{p}\right)$ calculated from yield line analysis of the collapse mechanisms were equal to $4 \pi M_{n}$ and $8 M_{n}$ for panels with fixed supports and simply supports, respectively, where $M_{n}$ is the flexural capacity per unit width.

\section{Idealized Bilinear Static Resistance}

Figure 8 shows the bilinear resistance function used to idealize the representative $P-\triangle$ The bilinear resistance function is defined by two anchor points: (i): the yield point $\left(X_{y}, R_{y}\right)$, and (ii) the ultimate point $\left(R_{u}, X_{u}\right)$. Calculating the yield force $\left(R_{y}\right)$ and the ultimate force $\left(R_{u}\right)$, and the corresponding displacements $\left(X_{y}\right.$ and $\left.X_{u}\right)$ would completely define the idealized bilinear resistance function for SC panels. The initial stiffness $\left(k_{1}\right)$ and post-yield stiffness $\left(k_{2}\right)$ are useful for defining the resistance function in the numerical solution of the equation of motion. These stiffness values are computed directly from the anchor point values using Equations 11 and 12.

The yield force $\left(R_{y}\right)$ and the ultimate force $\left(R_{u}\right)$ were expressed as factors $\left(\bar{C}_{P y}\right.$ and $\left.\bar{C}_{P u}\right)$ of the flexural capacity $\left(M_{n}\right)$ and the span length-to-thickness ratio $\left(L / t_{s c}\right)$ as shown in Equations 7 and 8. The corresponding yield displacement $\left(X_{y}\right)$ and the ultimate displacements $\left(X_{u}\right)$ were 
expressed as factors $\left(\bar{C}_{\Delta y}\right.$ and $\left.\bar{C}_{\Delta u}\right)$ of a nominal elastic displacement (force divided by $E I_{\text {eff }} / L^{2}$ ) multiplied by $t_{s c} / L$ as shown in Equation 9 and 10. The span length-to-thickness $\left(L / t_{s c}\right)$ parameter had to be included due to its significant influence on the $P-\Delta$ for panels with $L / t_{s c}$ ratios less than 10. For panels with $L / t_{s c}$ greater than 10 , the influence is negligible and 10 may be used in these equations.

$$
\begin{gathered}
R_{y}=\bar{C}_{P y} M_{n}\left(\frac{L}{t_{s c}}\right) \\
R_{u}=\bar{C}_{P u} M_{n}\left(\frac{L}{t_{s c}}\right) \\
X_{y}=\bar{C}_{\Delta y}\left(\frac{R_{y} L^{2}}{E I_{e f f}}\right)\left(\frac{t_{s c}}{L}\right) \\
X_{u}=\bar{C}_{\Delta u}\left(\frac{R_{u} L^{2}}{E I_{e f f}}\right)\left(\frac{t_{s c}}{L}\right) \\
k_{1}=\frac{R_{y}}{X_{y}} \quad \\
k_{2}=\frac{R_{u}-R_{y}}{X_{u}-X_{y}}
\end{gathered}
$$

In order to determine these coefficients, the $P-\Delta$ responses were normalized using Equations 13 and 14. As shown, the load $P$ was normalized with respect to $M_{n}$ multiplied by the $L / t_{s c}$ ratio, which is the inverse of the term in Equations 7 and 8 . The displacement $\Delta$ was normalized with respect to $P L^{2} / E I_{\text {eff }}$ multiplied by the $t_{s c} / L$ ratio, which is representative of the inverse of the term in Equations 9 and 10.

$$
C_{P}=\frac{P}{M_{n}\left(\frac{L}{t_{s c}}\right)}
$$




$$
C_{\Delta}=\frac{\Delta}{\left(\frac{P L^{2}}{E I_{e f f}}\right)\left(\frac{t_{s c}}{L}\right)}
$$

The $P-\Delta$ responses of the SC panels varied considerably in magnitude due to the influence of various material and geometric parameters, boundary conditions, span length etc. on the stiffness and strength of SC panels. However, when normalized using Equations 13 and 14, these $P-\Delta$ reduced to $C_{P}-\mathrm{C}_{\Delta}$ responses that were comparable and similar to each other. The $C_{P^{-}} C_{\Delta}$ responses were used to establish the anchor points, and determine the average values for the coefficients $\left(\bar{C}_{P y}, \bar{C}_{\Delta y}, \bar{C}_{P u}\right.$, and $\left.\bar{C}_{\Delta u}\right)$ defining the bilinear static resistance function.

Table 4 includes the forces and displacements corresponding to the occurrence of cracking event A $\left(P_{c r}\right.$ and $\left.\Delta_{c r}\right)$, yielding event B $\left(P_{y}\right.$ and $\left.\Delta_{y}\right)$, and event $\mathrm{C}\left(P_{u}\right.$ and $\left.\Delta_{u}\right)$. The corresponding values of the normalized forces and displacements $C_{P c r}$ and $C_{\Delta c r}$ for event $\mathrm{A}, C_{P y}$ and $C_{\Delta y}$ for event $\mathrm{B}$, and $C_{P u}$ and $C_{\Delta u}$ for event $\mathrm{C}$ are also included in Table 4 for all SC panels.

As mentioned in Table 4 (notes column), the analysis of six SC panel models terminated before failure due to numerical instabilities which could not be overcome. The reasons for the numerical instability were unclear, but it was potentially due to the complex interactions between the steel and concrete elements. Several techniques were used to overcome instabilities due to these complex interactions, and these techniques were successful for some models but not for all. A few models had shear failure that limited the force-displacement response. For example, the behavior of model number 6, F-35-3-4.2-12-0.5-5-50, was controlled by diagonal shear cracks that formed early during loading. This model had the smallest span length-to-wall thickness $\left(L / t_{s c}\right)$ ratio of 3, which made it shear dominant. The behavior of model numbers 14, 15 and 17-21 was controlled by diagonal shear cracks through the wall thickness. These diagonal cracks became horizontal at the top of the shear studs on the tension faceplate. These models had lower tie bar 
reinforcement ratios $\left(\rho_{t}\right.$ less than 0.5$)$, and larger tie bar spacing $\left(S / t_{s c}\right.$ greater than 0.5$)$, which could not prevent shear failure mode from governing the force-displacement response.

The values of $C_{P y}$ and $C_{\Delta a}$ for event $\mathrm{B}$, and $C_{P u}$ and $C_{\triangle a}$ for event $\mathrm{C}$ reported in Table 4 were used to compute the average values of $\bar{C}_{P y}, \bar{C}_{\Delta y}, \bar{C}_{P u}$, and $\bar{C}_{\Delta u}$ for different types of SC panel models. The statistical analysis of the values is provided in Table 5, which includes the average value $(\mu)$, standard deviation $(\sigma)$, and the coefficient of variation $(\mathrm{COV})$. For SC panels with simply supported edges, the average values of $\bar{C}_{P y}, \bar{C}_{\Delta y}, \bar{C}_{P u}$, and $\bar{C}_{\Delta u}$ were equal to 0.55 , 0.79, 0.98 and 2.50, respectively. The corresponding COV varies from $4-11 \%$.

For SC panels with fixed supported edges, the average values of of $\bar{C}_{P y}, \bar{C}_{\Delta y}, \bar{C}_{P u}$, and $\bar{C}_{\Delta u}$ were equal to $0.53,0.36,1.02$ and 1.74 , respectively. The corresponding COV varies from $19 \%$ - 44\%, which is quite high. The high COV results from the analyses that terminated early due to numerical instabilities, and models that were governed by shear failure due to low tie bar reinforcement ratios $\left(\rho_{t}\right)$ and large tie spacing, which can be prevented by adequate design and detailing. When these models were removed from the statistical evaluations, the average values of of $\bar{C}_{P y}, \bar{C}_{\Delta y}, \bar{C}_{P u}$, and $\bar{C}_{\Delta u}$ were equal to $0.55,0.49,1.25$ and 2.42 , respectively. The corresponding COV were from $7-17 \%$.

These final recommended values for the anchor points of the idealized bilinear static resistance function of $\bar{C}_{P y}, \bar{C}_{\Delta y}, \bar{C}_{P u}$, and $\bar{C}_{\Delta u}$ for SC panels are reported in Table 6 for different support conditions.

\section{Influence of Parameters}

Figures 9 - 16 compare the load-displacement responses of models 1-27 in Table 4 to evaluate the influence of various parameters. Each figure compares: (a) the $P-\Delta$ responses, and (b) 
the normalized $C_{P^{-}} C_{\Delta}$ curves for the models in specific groups that vary only one parameter, while keeping all other parameters relatively constant. The model identifiers are included in the figures, and the parameter being varied is highlighted for clarity. Additionally, the idealized bilinear resistance function developed using the factors $\left(\bar{C}_{P y}, \bar{C}_{\Delta y}, \bar{C}_{P u}\right.$, and $\left.\bar{C}_{\Delta u}\right)$ reported in Table 6 is included to compare with the $C_{P^{-}} C_{\Delta}$ curves.

Figure 9 compares the $P-\Delta$ responses from the analyses of models 1-5 in Table 4 , which varied only the panel thickness $\left(t_{s c}\right)$ from $12-48$ in., while keeping the remaining design parameters the same. As shown in Figure 9(a), the load and displacement capacities of the SC panels increase significantly with thickness $t_{s c}$. The $P-\Delta$ and $C_{P^{-}} C_{\Delta}$ curves for these models are quite comparable. Additionally, the bilinear resistance function compares reasonably with the $C_{P^{-}} C_{\Delta}$ curves, particularly after yielding. The stiffness before yielding varies considerably from the idealized resistance function, and this variation seems to be more significant for walls with smaller thickness $\left(t_{s c}\right)$. This also identifies $t_{s c}$ equal to $12 \mathrm{in}$. as the practical limit for the resistance function.

Figure 10 compares the $P-\triangle$ responses from the analyses of models 4 and 6-10 in Table 4, which varied only the $L / t_{s c}$ ratio from 3 - 15, while keeping all remaining parameters constant. As shown in Figure 10(a), the load and displacement capacities of the SC panels increase with the $L / t_{s c}$ ratio because of increased flexibility. This influence was most notable for $L / t_{s c}$ less than 10 . The $P-\Delta$ and $C_{P}-C_{\Delta}$ curves for these models are quite comparable. The bilinear resistance function compares reasonably with the $C_{P^{-}} C_{\Delta}$ curves, except for the model with the smallest $L / t_{s c}$ ratio of 3 , which failed in shear instead of flexure. This also identifies $L / t_{s c}$ ratio equal to 5 as the practical limit for the resistance function. 
Figure 11 compares the $P-\Delta$ responses from the analyses of models 4 and 11-12 in Table 4, which varied only the concrete compressive strength $\left(f_{c}^{\prime}\right)$ from 4 - 6 ksi, while keeping all remaining parameters constant. The concrete compressive strength $\left(f^{\prime}{ }_{c}\right)$ has modest influence on the load and displacement capacities, $P-\Delta$, of SC panels. The bilinear resistance function compares reasonably with the $C_{P^{-}} C_{\Delta}$ curves.

Figure 12 compares the $P-\Delta$ responses from the analyses of models 4 and 13-15 in Table 4, which varied only the faceplate yield strength $\left(F_{y}\right)$ from 50 - $65 \mathrm{ksi}$, while keeping all remaining parameters constant. The faceplate yield strength $\left(F_{y}\right)$ increases the load capacity slightly, and reduces the displacement capacity due to reduced material ductility. The bilinear resistance function compared reasonably with the $C_{P}-C_{\Delta}$ curves, but the displacement capacity of SC panels with $65 \mathrm{ksi}$ yield strength faceplates is much lower. This also identified faceplate yield strength equal to $65 \mathrm{ksi}$ as the practical limit for the resistance function.

Figure 13 compares the $P-\Delta$ responses from the analyses of models 4 and 16-18 in Table 4, which varied only the faceplate reinforcement ratio $(\rho)$ from $2.1-4.9 \%$. Most other parameters were constant, but the tie bar reinforcement ratio $\left(\rho_{t}\right)$ also varied from $0.14-0.74 \%$, and the plate slenderness $\left(s / t_{p}\right)$ ratio varied from $10.3-14.4$. The plate slenderness $\left(s / t_{p}\right)$ ratio and tie reinforcement $\left(\rho_{t}\right)$ ratio had to be varied to meet the minimum section detailing requirements of AISC N690s1-15 as mentioned earlier. Figure 13(a) shows that the load-displacement response of SC panels increases with the faceplate reinforcement ratio $(\rho)$, but the response was interrupted by horizontal shear failure due to the reduced tie reinforcement ratio ( $\rho_{t}$ less than 0.5$)$ for models 16 and 17, and numerical instability for model 18 . The $P-\Delta$ and $C_{P^{-}} C_{\Delta}$ curves were similar to each other, and compared reasonably with the bilinear resistance function before termination due to shear failure (instead of flexural failure). 
Figure 14 compares the $P$ - $\triangle$ responses from the analyses of models 4,19 , and 20 in Table 4 , which varied only the slenderness ratio $\left(s / t_{p}\right)$ ratio from $12-24$, while keeping most other parameters constant. The faceplate reinforcement ratio $(\rho)$ was equal to $2.1 \%$, and the tie reinforcement ratio $\left(\rho_{t}\right)$ was equal to $0.14 \%$. All the SC panel models failed in shear, and the $P-\Delta$ and $C_{P}-C_{\Delta}$ curves did not compare well with the bilinear resistance function because of early termination due to shear failure. Similarly, Figure 15 compares the $P-\Delta$ responses from the analyses of models 4 and 21-23 in Table 4 , which varied only the tie bar spacing ratio $\left(S / t_{s c}\right)$ from 0.63 to 1.46 , while keeping most other parameters constant. The faceplate reinforcement ratio $(\rho)$ was equal to $2.1 \%$, and the plate slenderness $\left(s / t_{p}\right)$ ratio was equal to 20 , but the tie reinforcement ratio $\left(\rho_{t}\right)$ reduced from 0.09 to 0.02 . As expected, these models also failed in shear, and the $C_{P}-C_{\Delta}$ curves did not compare well with the bilinear resistance function because of early termination due to shear failure.

Figure 16 compares the $P-\Delta$ responses from the analyses of models $24-27$ in Table 4, which had simply supported ends. The wall thickness $\left(t_{s c}\right)$ changed from $12-48$ in., while keeping the remaining design parameters the same. As shown in Figure 16(a), the load and displacement capacities of the SC panels increase significantly with $t_{s c}$. The $P-\Delta$ and $C_{P}-C_{\Delta}$ curves for these models were quite comparable. The bilinear resistance function, developed using the coefficients for simply supported end conditions in Table 6, compares reasonably well with the $C_{P}-C_{\Delta}$ curves, particularly after yielding. The stiffness before yielding varies considerably from the idealized resistance function, and this variation seems to be more significant for walls with smaller $t_{s c}$. 


\section{SDOF Analysis of SC Walls}

\section{Mass Transformation Factor}

The mass transformation factor, $K_{M}$, for an RC panel with fixed edges and concentrated load acting at the center is equal to 0.16 [20]. The value of $K_{M}$ for the case of concentrated load acting at the center of a simply supported RC panel with simply supported edges is not provided in the literature, but it can be calculated using the deflected shape $\Phi(x, y)$ as shown in Equation 6. The deflected shape, cracking pattern, and yield lines for SC panels were similar to those for RC panels, but the static resistance function for SC panels is bilinear with hardening after yielding (Figure 8), which is different from the elasto-plastic resistance function used typically for RC panels (Figure 2). Therefore, the mass transformation factors, $K_{M}$, for SC panels were calculated using Equation 6 for both: (i) SC panels with fixed edges, and (ii) SC panels with simply supported edges.

Since the normalized $C_{P^{-}} C_{\Delta}$ responses were similar for SC panels with different material and geometric parameters, $K_{M}$ was computed using one model (Model 4) for panels with fixed edges, and one model (Model 24) for panels with simply supported edges. $K_{M}$ was computed numerically by multiplying the square of the deflection of each node on the central plane of the model by the tributary surface area of the node. $K_{M}$ was computed twice for each model: (i) in the elastic range of response (after concrete cracking event $A$, but before yielding event $B$ ), and (ii) in the inelastic range of the response (after yielding event $B$, but before rupture event $C$ ). The resulting values of $K_{M E}$ (elastic range) and $K_{M P}$ (inelastic range) are shown in Table 7 for both panels with fixed edges and simply supported edges.

\section{Limitations}


The SDOF model is used to calculate the maximum deflection of SC panels subjected to impactive or impulsive loading [28]. The calculated response depends on the assumed resistance function, $R(y)$, and the maximum deflection is used to estimate the required displacement ductility and rotation capacity for panel structures. The resistance function, $R(y)$, accounts for flexural behavior and the associated steel yielding limit state and steel rupture failure mode. It does not account for shear failure modes because they are non-ductile as shown in Figure 14 and 15. As mentioned earlier, models with shear failure modes were excluded from the calculation of the average coefficients $\bar{C}_{P y}, \bar{C}_{\Delta y}, \bar{C}_{P u}$, and $\bar{C}_{\Delta u}$ used to define the static resistance function.

The SDOF model also does not evaluate the structural performance (flexural or shear behavior) of the panel structure. The SDOF equation of motion is solved numerically to calculate the displacement and resistance time histories. The maximum resistance can be used to estimate the shear force near the edges of the panel. The panel can be designed and detailed to resist this maximum shear force, or conservatively the shear force associated with ultimate resistance, $R_{u}$ [21]. The SDOF method does not account for punching shear failure in the vicinity of the impact load and this design consideration must be checked separately from SDOF analysis.

\section{Comparison of Impact Analysis Results}

The response of SC panels subjected to (dynamic) missile impact was calculated using the finite element models described earlier, where the models were modified slightly to include strain rate effects on the concrete and steel materials. Concrete strain rate effects were included using the built-in rate effects in the Winfrith concrete model. The only material property that changed for this was fracture energy $\left(G_{f}\right)$, which was provided directly as the input rather than the crack opening width $(w)$. Strain rate effects for steel were included using a curve relating the 
strain rate to an increase factor applied to the yield strength. The values for this curve were taken from [21]. The finite element models were analyzed for missile impact from a $9500 \mathrm{lb}, 94 \mathrm{in.}$ diameter cylindrical rigid part with an initial velocity of $150 \mathrm{ft} / \mathrm{sec}$. Table 8 includes the identifier and model number of the six SC panels that were analyzed for dynamic missile impact. These SC panels were selected from those included in the earlier parametric studies with complete details listed in Table 3.

The response of these SC panels subjected to dynamic missile impact was also calculated using the SDOF models described earlier. The force, $F(t)$, applied to the SDOF model was taken from the finite element model projectile contact force, which was nearly identical for all models. $F(t)$ had a peak value of 120,000-kips and decreased to zero over approximately 1-msec. The resistance function for each model was calculated based on its cross-sectional properties listed in Table 3 and included dynamic increase factors (DIF) for $f^{\prime}{ }_{c}$ and $F_{y}$ taken from [21]. The calculated values of $R_{y}$, initial stiffness $k_{1}$, post-yield stiffness $k_{2}$, and the panel weight $W_{\text {panel }}$, are provided in Table 8 .

The results from the finite element analyses and the SDOF analyses in terms of the maximum displacement $\left(X_{F E M}\right.$ and $\left.X_{S D O F}\right)$ and the total reaction force $\left(R_{F E M}\right.$ and $\left.R_{S D O F}\right)$ are reported in Table 8 for comparison. As shown, five of the six cases were in close agreement for maximum deflection. The SDOF analysis for Model 27 calculated a smaller displacement than the finite element model because the deflected shape under the impact load was significantly different from the deflected shape used to calculate $K_{M}$. The reason for this is related to the ratio of the missile diameter to the span length. Model 27 was longer than the other five panels so the ratio of missile diameter to length was lower leading to more localized deflection than the other five panels. In other words, much less mass was engaged than estimated using the mass factor 
determined from the static analyses. For all cases, SDOF analysis calculated smaller total reactions than the FEM with the result for Model 27 being much lower than the other five.

\section{Summary and Conclusions}

This paper presented the development of a single degree of freedom (SDOF) model approach to calculate the maximum displacement response of SC panels subjected to missile impact loading and designed to prevent local perforation failure of the wall using [11]. The SDOF model was developed and calibrated using 3D finite element analysis models, results, and parametric studies. The 3D finite element models of SC panels were based on those developed and benchmarked previously by the authors for local perforation studies. These models were modified slightly for the maximum displacement studies presented in this paper, and benchmarked using large-scale experimental results for out-of-plane behavior of SC beams.

The benchmarked models were used to conduct parametric studies using 27 different models of SC panels with variations in geometric properties (wall thickness $t_{s c}$, span length-tothickness $L / t_{s c}$ ratio), material properties (faceplate yield strength $F_{y}$, concrete compressive strength $f_{c}^{\prime}$ ), section detailing parameters (faceplate reinforcement ratio $\rho$, plate slenderness $s / t_{p}$, tie bar reinforcement ratio $\rho_{t}$, and tie bar spacing $S / t_{s c}$ ), and boundary conditions (rotational fixity of supports). All the SC panels were designed and detailed in accordance with AISC N690s1-15 [4], and the range of values for the parameters were practical for nuclear design. All the models were analyzed for monotonically increasing concentrated loading acting at the center with loading diameter-to-span length ratio of 0.25 . The resulting $P-\Delta$ responses were compared, and then normalized to $C_{P}-C_{\Delta}$ responses, which implicitly accounted for the dominant parameters. 
The normalized $C_{P^{-}} C_{\Delta}$ responses were almost identical for the models with flexure dominant response.

The parametric studies indicated that the $P-\Delta$ and $C_{P}-C_{\Delta}$ responses for models with flexure dominant response include three major events: (i) concrete shear cracking event $A$, (ii) steel faceplate yielding event $B$, and (iii) steel faceplate rupture event $C$. The concrete shear cracking event A occurs very early in the response, and a bilinear idealization that is defined by the yielding event $\mathrm{B}$ and rupture event $\mathrm{C}$ is adequate for $\mathrm{SC}$ panels with fixed or simply supported edges. The ultimate strength $\left(R_{u}\right)$ of SC panels (associated with faceplate rupture event C) increases with the span length-to-wall thickness $\left(L / t_{s c}\right)$ ratio, up to $L / t_{s c}$ equal to 10 , after which it remains approximately constant at the plastic load $\left(P_{p}\right)$ associated with the plastic collapse mechanism of the panel calculated using yield line analysis. The plastic collapse mechanism for SC panels with fixed edges consists of radial yield lines and concrete cracking pattern, while the mechanism for panels with simply supported edges consists of diagonal (corner to corner) yield lines and cracking pattern.

The concrete compressive strength does not have a significant influence on the loaddisplacement responses. The steel yield strength and the reinforcement ratio influence the loaddisplacement responses depending on their direct influence on the yielding and rupture events and the moment capacity per unit width, $M_{n}$. The section detailing parameters such as the plate slenderness $s / t_{p}$ ratio, tie bar reinforcement $\rho_{t}$ ratio, and the tie bar spacing $S / t_{s c}$ ratio have a significant influence on the load-displacement responses and governing failure mode. Shear failure was the dominant failure mode for models with lower tie bar reinforcement $\rho_{t}$ ratio and larger tie bar spacing $S / t_{s c}$ ratio. These models with shear failure were not included in the development of the idealized bilinear resistance function for SDOF models. As a result, the 
SDOF models and approach are limited to SC panels with flexure dominant response, which can be obtained with adequate detailing (higher $\rho_{t}$ ratios or smaller $S / t_{s c}$ ratios).

The anchor points for the bilinear resistance function, namely, the yield point $\left(R_{y}, X_{y}\right)$ and the rupture point $\left(R_{u}, X_{u}\right)$, were established using the normalized $C_{P}-C_{\Delta}$ responses of all models with flexure dominant response. The bilinear resistance function with these anchor points (and the equations for calculating them) are recommended for calculating the global displacement response of SC panels with: (i) the typical range of design parameter used in nuclear design, (ii) designed according to AISC N690s1-15, and (iii) detailed to have flexure dominant response.

The displaced shapes from the finite element analysis of the SC panels were used to determine the effective mass, $M_{e}$, and associated mass transformation factors, $K_{M}$, for the SDOF models of SC panels. These values were reported in the paper for SC panels with: (i) different boundary conditions (fixed edges and simply supported edges), (ii) subjected to central concentrated loading, and (iii) for responses within the elastic range $\left(K_{M E}\right)$ and the inelastic range $\left(K_{M P}\right)$.

The SDOF models and analysis approach were used to predict the behavior of six SC panels subjected to missile impact loading. The responses were compared with those obtained from 3D finite element analysis of dynamic missile impact that implicitly accounted for the effects of strain rate on concrete and steel material properties. Comparisons indicate that the SDOF models predict the maximum (total) displacement with reasonable accuracy. However, for models with missile diameter to span length ratio less than 0.25 , there were significant localized effects in the 3D finite element models, which were not accounted in the SDOF models.

\section{Future Work}


There are several important aspects of this work that require additional investigation. Additional research of the available ductility of SC panels with various end conditions is required to define appropriate limits for these structural elements. Current research indicates that the ductility of SC panels is comparable to the ductility of $\mathrm{RC}$ panels, but additional experimental and analytical investigation is critical for finalization of design limits.

Prior research has evaluated the local performance of SC walls to missile impact, and developed a design method to prevent local perforation. Current research focused on the response of SC walls designed to prevent local perforation and the development of SDOF models to calculate maximum displacement. However, it did not account adequately for cases with significant highly localized inelastic deformations which increase in likelihood as the ratio of the missile diameter to panel thickness gets smaller. Preliminary results discussed by the authors in [30] suggest that these highly localized deformations may be modeled by adding another degree of freedom, which accounts for local deformation, to the SDOF model described herein. Future research should focus on identifying where these highly localized deformations are relevant, and calibrating the two degree of freedom modeling approach for these cases.

It is well known that $\mathrm{RC}$ structural elements require more shear reinforcement to resist blast and impact loads than necessary for conventional loads. The same is expected to be true of SC structural elements. Additional work is necessary to develop recommendations to improve impact resistant detailing specifically to improve shear strength, which in turn will improve member ductility. It is important that future work include investigations of SC wall intersections or connections. If these are not properly detailed to transmit the dynamic loads imparted by impact and blast loads, then local perforation resistance and global behavior will be of secondary concern. 


\section{Acknowledgements}

The authors thank Dr. Bill Johnson and Dr. Damon Reigles for their helpful suggestions and conversations which had a positive influence on the contents of this paper. Partial funding was provided by DOE (Grant Number DE-NE0008201), NRC (Grant Number NRC-HQ-60-14-G0001), AISC, and Purdue University. 


\section{References}

[1] C. Schlaseman, Application of Advanced Construction Technologies to New Nuclear Power Plants (MPR-2610, Revision 2), Washington, D.C., 2004. http://pbadupws.nrc.gov/docs/ML0931/ML093160836.pdf.

[2] Mitsubishi Heavy Industries, Design Control Document for the US-APWR, Tokyo, Japan, 2011. http://pbadupws.nrc.gov/docs/ML1109/ML110980211.pdf (accessed May 7, 2013).

[3] Westinghouse Electric Company, Westinghouse AP1000 Design Control Document Rev. 17, Cranberry Township, PA, 2008. http://pbadupws.nrc.gov/docs/ML0832/ML083230868.html (accessed May 7, 2013).

[4] American Institute of Steel Construction, Specification for Safety-Related Steel Structures for Nuclear Facilities Including Supplement No. 1 (ANSI/AISC N690s1-15), (2015) 201.

[5] A.H. Varma, S.R. Malushte, K.C. Sener, Z. Lai, Steel-plate composite (SC) walls for safety related nuclear facilities: Design for in-plane forces and out-of-plane moments, Nucl. Eng. Des. 269 (2014) 240-249. doi:10.1016/j.nucengdes.2013.09.019.

[6] K. Zhang, A.H. Varma, S.R. Malushte, S. Gallocher, Effect of shear connectors on local buckling and composite action in steel concrete composite walls, Nucl. Eng. Des. 269 (2014) 231-239. doi:10.1016/j.nucengdes.2013.08.035.

[7] K.C. Sener, A.H. Varma, D. Ayhan, Steel-plate composite (SC) walls: Out-of-plane flexural behavior, database, and design, J. Constr. Steel Res. 108 (2015) 46-59. doi:10.1016/j.jcsr.2015.02.002.

[8] K.C. Sener, A.H. Varma, Steel-plate composite walls: Experimental database and design for out-of-plane shear, J. Constr. Steel Res. 100 (2014) 197-210. doi:10.1016/j.jcsr.2014.04.014.

[9] J. Seo, A.H. Varma, K.C. Sener, D. Ayhan, Steel-Plate Composite (SC) Walls: In-Plane Shear Behavior, Database, and Design, J. Constr. Steel Res. Submitted (2015).

[10] S.R. Bhardwaj, A.H. Varma, T. Al-Shawaf, Outline of Specification for Composite SC Walls in Nuclear Facilities, in: Struct. Congr. 2015, American Society of Civil Engineers, Portland, OR, 2015.

[11] J.C. Bruhl, A.H. Varma, W.H. Johnson, Design of composite SC walls to prevent perforation from missile impact, Int. J. Impact Eng. 75 (2015) 75-87. doi:10.1016/j.ijimpeng.2014.07.015. 
[12] U.S. Nuclear Regulatory Commission, Regulatory Guide 1.142, Revision 2, "SafetyRelated Concrete Structures for Nuclear Power Plants (Other Than Reactor Vessels and Containments)," (2001) 1-14.

[13] J. Mizuno, E. Tanaka, I. Nishimura, N. Koshika, A. Suzuki, Y. Mihara, Investigation on Impact Resistance of Steel Plate Reinforced Concrete Barriers Against Aircraft Impact Part 3 $\square$ : Analyses of Full-Scale Aircraft Impact, in: 18th Int. Conf. Struct. Mech. React. Technol. (SMiRT 18), Beijing, China, 2005: pp. 2591-2603. http://www.iasmirt.org/transactions/18/J05_3.pdf.

[14] H. Grisaro, A. Dancygier, Assessment of the perforation limit of a composite RC barrier with a rear steel liner to impact of a non-deforming projectile, Int. J. Impact Eng. 64 (2014) 122-136. doi:10.1016/j.ijimpeng.2013.10.002.

[15] H. Tsubota, Y. Kasai, N. Koshika, H. Morikawa, T. Uchida, T. Ohno, Quantitative Studies on Impact Resistance of Reinforced Concrete Panels with Steel Liners under Impact Loading Part 1: Scaled Model Impact Tests, in: 12th Int. Conf. Struct. Mech. React. Technol. (SMiRT 12), Stuttgart, Germany, 1993: pp. 169-174. http://www.iasmirt.org/transactions/12/J07-1.pdf (accessed August 27, 2013).

[16] T.A. Walter, A.M. Wolde-Tinsae, Turbine missile perforation of reinforced concrete, J. Struct. Eng. 110 (1984) 2439-2455. doi:10.1061/(ASCE)0733-9445(1984)110:10(2439).

[17] K.M. a. Sohel, J.Y.R. Liew, Steel-Concrete-Steel sandwich slabs with lightweight core -Static performance, Eng. Struct. 33 (2011) 981-992. doi:10.1016/j.engstruct.2010.12.019.

[18] K.M. a. Sohel, J.Y.R. Liew, Behavior of steel-concrete-steel sandwich slabs subject to impact load, J. Constr. Steel Res. 100 (2014) 163-175. doi:10.1016/j.jcsr.2014.04.018.

[19] J.M. Biggs, Introduction to Structural Dynamics, McGraw-Hill, New York, NY, 1964.

[20] American Society of Civil Engineers, Structural Analysis and Design of Nuclear Plant Facilities (ASCE - Manuals and Reports on Engineering Practice - No. 58), American Society of Civil Engineers, New York, NY, 1980.

[21] U.S. Department of Defense, Structures to Resist the Effects of Accidental Explosions (UFC 3-340-02), (2008) 1943. http://www.wbdg.org/ccb/DOD/UFC/ufc_3_340_02.pdf.

[22] J.D. Riera, A Critical Reappraisal of Nuclear Power Plant Safety Against Accidental Aircraft Impact, Nucl. Eng. Des. 57 (1980) 193-206. doi:10.1016/0029-5493(80)90233-2.

[23] Nuclear Energy Institute, Methodology for Performing Aircraft Impact Assessments for New Plant Designs (NEI 07-13 Revision 8P), Walnut Creek, CA, 2011. http://pbadupws.nrc.gov/docs/ML1114/ML111440006.pdf. 
[24] American Concrete Institute, Code Requirements for Nuclear Safety-Related Concrete Structures (ACI 349-06) and Commentary, American Concrete Institute, Farmington Hills, MI, 2007.

[25] W. Johnson, J. Bruhl, D. Reigles, J. Li, A. Varma, Missile Impact on SC Walls: Global Response, in: Struct. Congr. 2014, American Society of Civil Engineers, Reston, VA, 2014: pp. 1403-1414. doi:10.1061/9780784413357.124.

[26] A.K. Chopra, Dynamics of Structures: Theory and Applications to Earthquake Engineering, 2nd ed., Prentice Hall, Upper Saddle River, NJ, 2001.

[27] J. Hallquist, LS-DYNA theory manual, Livermore Technology Software Corporation, Livermore, CA, 2006. http://www.dynasupport.com/manuals/additional/ls-dyna-theorymanual-2005-beta/at_download/file (accessed March 12, 2013).

[28] J.C. Bruhl, Behavior and Design of Steel-Plate Composite (SC) Walls for Blast Loads, Purdue University, 2015.

[29] W.C. Young, R.G. Budynas, A.M. Sadegh, Roark's Formulas for Stress and Strain, 8th ed., McGraw-Hill, 2012. http://accessengineeringlibrary.com/browse/roarks-formulas-forstress-and-strain-eighth-edition (accessed October 11, 2014).

[30] J.C. Bruhl, W.H. Johnson, D.G. Reigles, J.M. Kim, J. Li, A.H. Varma, Impact Assessment of SC Walls Using Idealized SDOF and TDOF Models, in: Struct. Congr. 2015, Portland, OR, 2015.

[31] American Concrete Institute, Building Code Requirements for Structural Concrete (ACI 318-11) and Commentary, American Concrete Institute, Farmington Hills, MI, 2011.

[32] F. Wittmann, Crack formation and fracture energy of normal and high strength concrete, Sadhana. 27 (2002) 413-423. doi:10.1007/BF02706991.

[33] C.-S. Shim, P.-G. Lee, T.-Y. Yoon, Static behavior of large stud shear connectors, Eng. Struct. 26 (2004) 1853-1860. doi:10.1016/j.engstruct.2004.07.011.

[34] J.G. Ollgaard, R.G. Slutter, J.W. Fisher, Shear strength of stud connectors in lightweight and normal-weight concrete, AISC Eng. J. April (1971) 55-64. http://structureshandouts.unomaha.edu/AISC/ProgramFilesFolder/AISC/Companion/bin/p df/ej/ollgaard1971Q1.pdf (accessed May 23, 2013).

[35] American Institute of Steel Construction, Specification for Structural Steel Buildings (ANSI/AISC 360-10), American Institute of Steel Construction, Chicago, IL, 2010. 


\begin{tabular}{|c|c|c|}
\hline Input for MAT_084/085 (Concrete) & Value or Equation Used & Reference \\
\hline Mass Density, RO (lbf:sec$\left.{ }^{2} / \mathrm{in}\right)$ & $2.36 \times 10^{-4}$ & \\
\hline Initial Tangent Modulus, TM ( $p s i)$ & $57000 \sqrt{f_{c}^{\prime}}$ & {$[31]$} \\
\hline Poisson's Ratio, PR & 0.15 & \\
\hline Uniaxial Compressive Strength, UCS ( $p s i$ ) & $1.25 \cdot \sqrt{f_{c}^{\prime}}$ & \\
\hline Uniaxial Tensile Strength, UTS (psi) & $2.5 \sqrt{f_{c}^{\prime}}$ & \\
\hline \multirow[t]{2}{*}{ Crack Width at Zero Tensile Strength, FE (in) } & $2 \cdot G_{f} / U T S$ & \\
\hline & $G_{f}=1.297\left(\Phi_{\max }\right)^{0.32}$ & {$[32]$} \\
\hline Aggregate Radius, ASIZE (in) & $\Phi_{\max } / 2$ & \\
\hline Rate Effects $(0=\mathrm{ON}, 1=\mathrm{OFF})$ & 1 & \\
\hline Unit Conversion, CONM & $-1=l b f \cdot \sec ^{2} /$ in, in, sec & \\
\hline \multicolumn{3}{|c|}{ Inputfor MAT_024 (Steel Plate, Tie Bars, and Shear Studs) } \\
\hline Mass Density, RO $\left(l b f \cdot \sec ^{2} / \mathrm{in}\right)$ & $7.33 \times 10^{-4}$ & \\
\hline Young's Modulus, E (psi) & $29 \times 10^{6}$ & \\
\hline Poisson's Ratio, PR & 0.30 & \\
\hline Plastic Strain at Failure, FAIL & 0.05 & \\
\hline Load Curve, LCSS (true stress - plastic strain) & based on material properties (Tables $2 \& 3$ ) & \\
\hline \multicolumn{3}{|c|}{ Input for MAT_074 (Connector Elements for Tie Bars and Shear Studs) } \\
\hline Mass Density, RO $\left(l b f \cdot \sec ^{2} / i n\right)$ & $7.33 \times 10^{-4}$ & \\
\hline Displacement at Failure, TDF & $\Delta_{\max }=\left(0.48-0.029 \cdot f_{c}^{\prime}\right) d_{s}$ & [33] \\
\hline Load Curve, FLCID (Load-Slip Relationship) & $\begin{array}{c}Q=Q_{n}\left(1-\mathrm{e}^{-18 \Delta}\right)^{2 / 5} \\
Q_{n}=0.65 \cdot A_{s} \cdot f_{u}\end{array}$ & $\begin{array}{l}{[34]} \\
{[35]}\end{array}$ \\
\hline \multicolumn{3}{|c|}{ Input for MAT_020 (Supports and Load Plates) } \\
\hline Mass Density, RO $\left(l b f \cdot \sec ^{2} / i n\right)$ & $7.33 \times 10^{-4}$ & \\
\hline Young's Modulus, E (psi) & $29 \times 10^{6}$ & \\
\hline Poisson's Ratio, PR & 0.30 & \\
\hline Constraints, $\mathrm{CMO}$ & $\begin{array}{c}1.0=\text { constraints applied using global } \\
\text { coordinates }\end{array}$ & \\
\hline Translation Constraints & $4=\mathrm{x}, \mathrm{y}$ constrained $7=\mathrm{x}, \mathrm{y}, \mathrm{z}$ constrained & \\
\hline Rotation Constraints & $7=\mathrm{x}, \mathrm{y}, \mathrm{z}$ constrained & \\
\hline
\end{tabular}

Table 1: Material Properties for LS-DYNA Models 


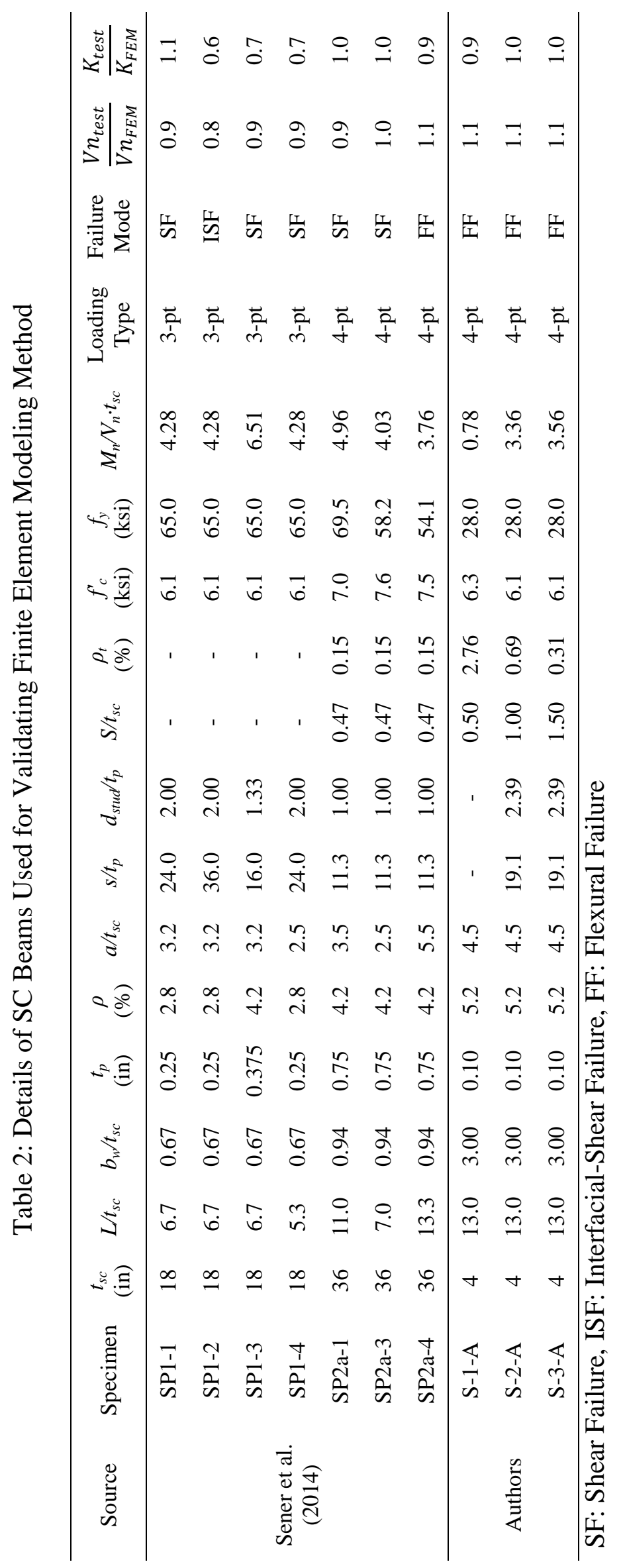




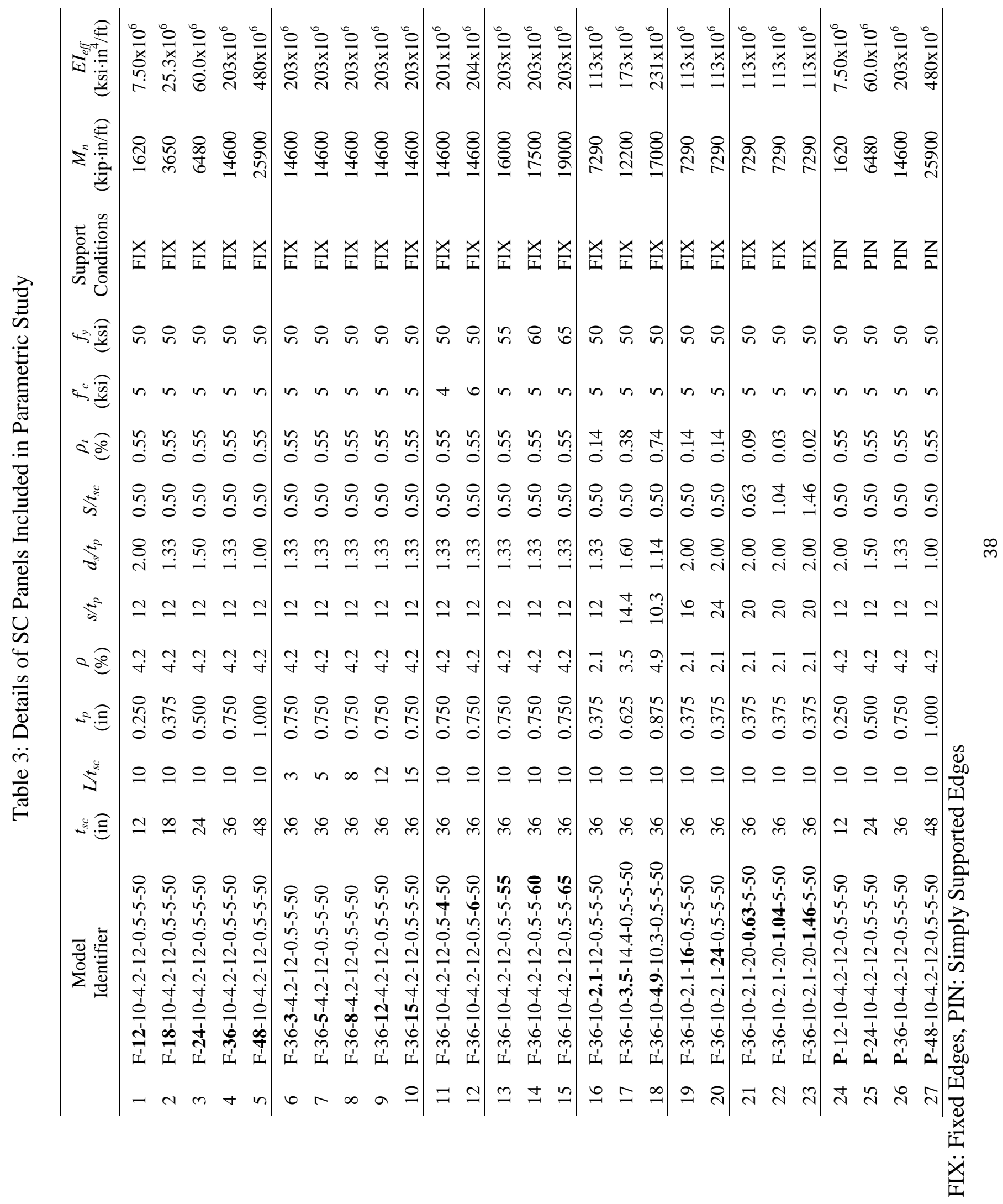




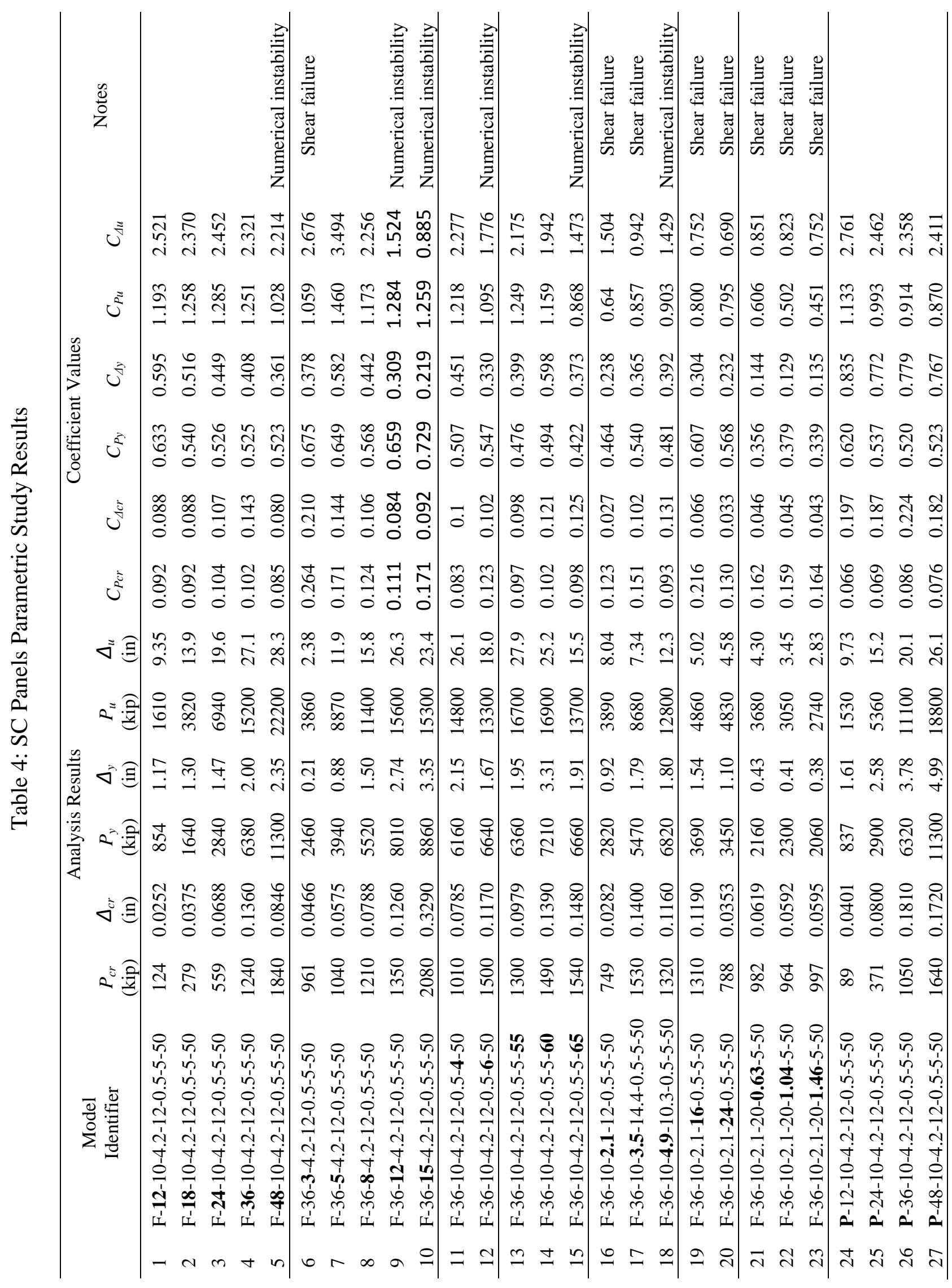


Table 5: Statistical Evaluation of Anchor Point Coefficients for Static Resistance Function

\begin{tabular}{ccccc|cccc|ccccc}
\hline \multicolumn{3}{c|}{ Simply Supported } & \multicolumn{5}{c|}{ Fixed Edges } & \multicolumn{3}{c}{ Fixed Edges (Reduced) } \\
& $C_{P y}$ & $C_{\Delta y}$ & $C_{P u}$ & $C_{\Delta u}$ & $C_{P y}$ & $C_{\Delta y}$ & $C_{P u}$ & $C_{\Delta u}$ & $C_{P y}$ & $C_{\Delta y}$ & $C_{P u}$ & $C_{\Delta u}$ \\
\hline$\mu$ & 0.55 & 0.79 & 0.98 & 2.50 & 0.53 & 0.36 & 1.02 & 1.74 & 0.55 & 0.49 & 1.25 & 2.42 \\
$\sigma$ & 0.04 & 0.03 & 0.1 & 0.16 & 0.10 & 0.14 & 0.28 & 0.76 & 0.06 & 0.08 & 0.08 & 0.41 \\
COV & 0.08 & 0.04 & 0.11 & 0.07 & 0.19 & 0.38 & 0.27 & 0.44 & 0.11 & 0.16 & 0.07 & 0.17 \\
& & & & & & & & & & & & \\
\hline
\end{tabular}

Table 6: Average Coefficients for Anchor Points of Idealized Resistance Function

\begin{tabular}{ccccc}
\hline Support Case & $\bar{C}_{P y}$ & $\bar{C}_{\Delta y}$ & $\bar{C}_{P u}$ & $\bar{C}_{\Delta u}$ \\
\hline Fixed Edges & 0.55 & 0.49 & 1.25 & 2.42 \\
Simple Supports & 0.55 & 0.79 & 0.98 & 2.50 \\
\hline
\end{tabular}

Table 7: Mass Factors for Central Concentrated Load on Square SC Panels

\begin{tabular}{ccc}
\hline Support Case & $K_{M E}$ & $K_{M P}$ \\
\hline Fixed Edges & 0.14 & 0.10 \\
Simple Supports & 0.20 & 0.10 \\
\hline
\end{tabular}


Table 8: SC Panel Impact Study Results

\begin{tabular}{ccccccccc}
\hline $\begin{array}{c}\text { Model } \\
\text { Number }\end{array}$ & $\begin{array}{c}R_{y} \\
\text { (kips) }\end{array}$ & $\begin{array}{c}k_{1} \\
(\mathrm{kip} / \mathrm{in})\end{array}$ & $\begin{array}{c}k_{2} \\
(\mathrm{kip} / \mathrm{in})\end{array}$ & $\begin{array}{c}W_{\text {panel }} \\
(\mathrm{kips})\end{array}$ & $\begin{array}{c}X_{F E M} \\
(\mathrm{in})\end{array}$ & $\begin{array}{c}X_{\text {SDOF }} \\
(\mathrm{in})\end{array}$ & $\begin{array}{c}R_{F E M} \\
\text { (kips) }\end{array}$ & $\begin{array}{c}R_{\text {SDOF }} \\
\text { (kips) }\end{array}$ \\
F-36-10-4.2-12-0.5-5-50 & 6640 & 2640 & 330 & 417 & 4.24 & 4.29 & 7590 & 6640 \\
F-36-10-4.2-12-0.5-4-50 & 6640 & 2620 & 330 & 417 & 4.19 & 4.30 & 7620 & 6640 \\
F-36-10-4.2-12-0.5-6-50 & 6640 & 2660 & 330 & 417 & 4.29 & 4.28 & 7900 & 6640 \\
F-36-10-4.2-12-0.5-5-65 & 8630 & 2640 & 330 & 417 & 4.08 & 3.91 & 7910 & 8630 \\
P-36-10-4.2-12-0.5-5-50 & 6690 & 1650 & 280 & 417 & 4.19 & 4.97 & 8030 & 6690 \\
F-36-15-4.2-12-0.5-5-50 & 9960 & 1760 & 220 & 939 & 4.21 & 3.15 & 8070 & 5540 \\
\hline
\end{tabular}




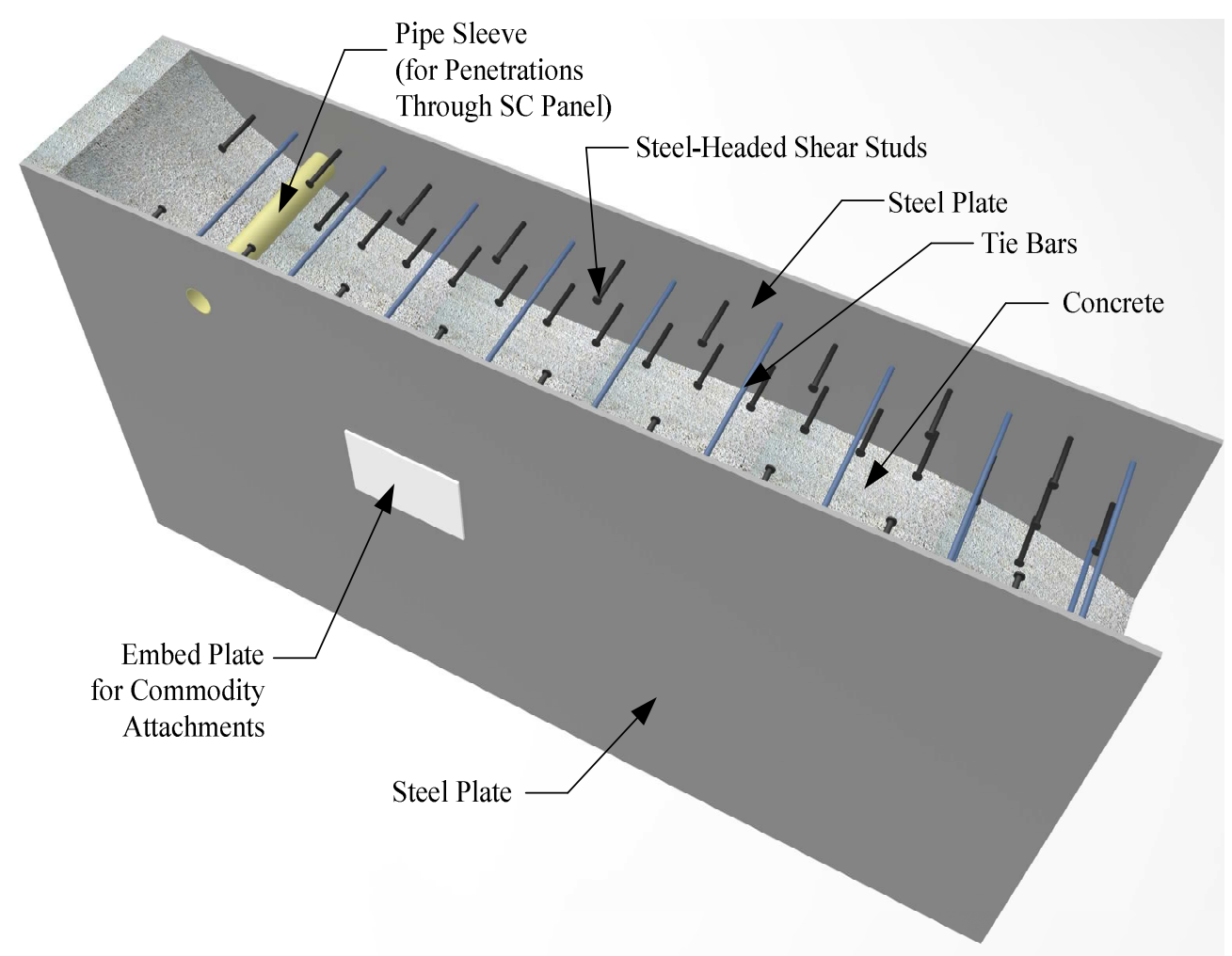

Figure 1: Typical SC Wall construction (from [25])

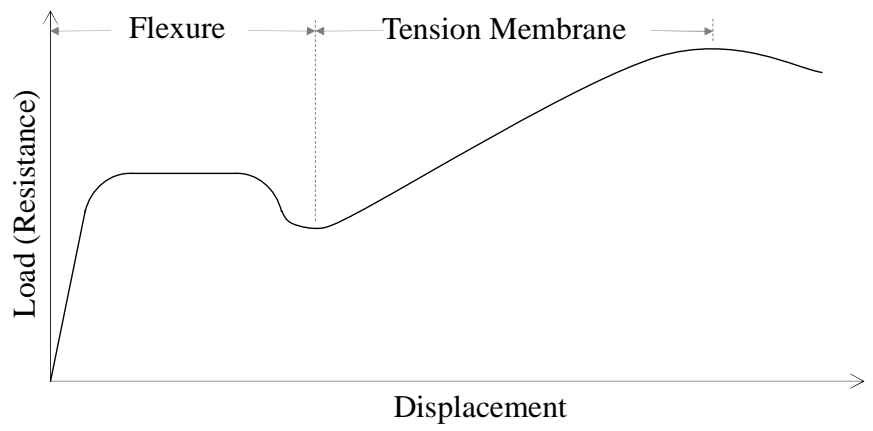

(a) Typical Behavior (after (U.S. Department of Defense, 2008))

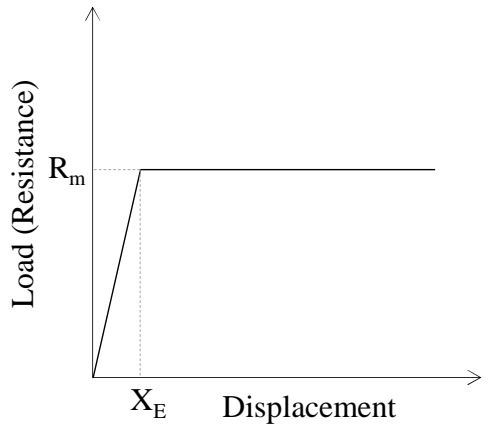

(b) Idealized Behavior

Figure 2: RC Load-Displacement Relationship 


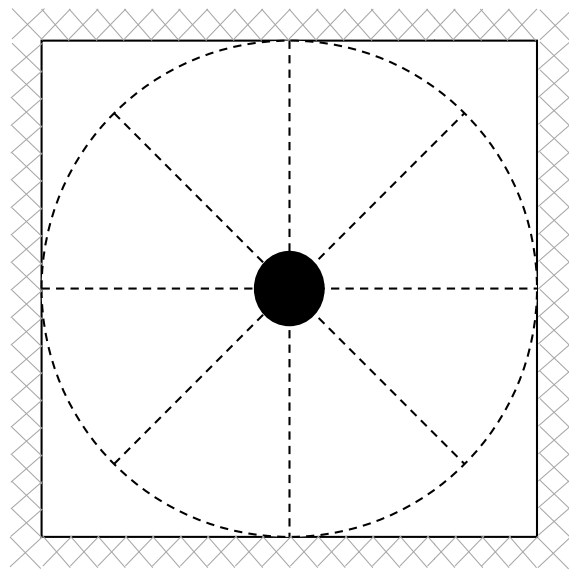

Fixed Edges

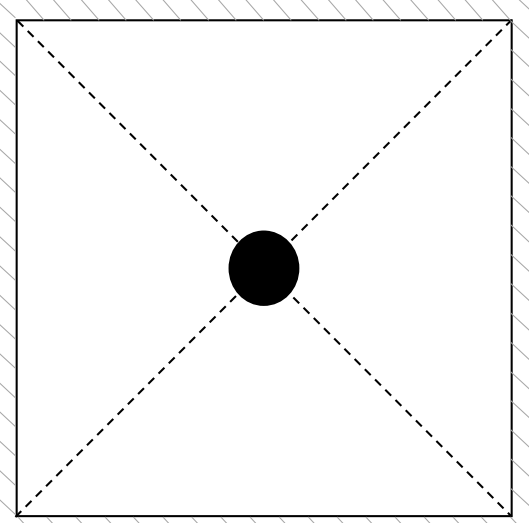

Simply Supported

Figure 3: Yield Lines for SC Panels with Central Concentrated Loads: (a) fixed edges, (b) simply supported edges

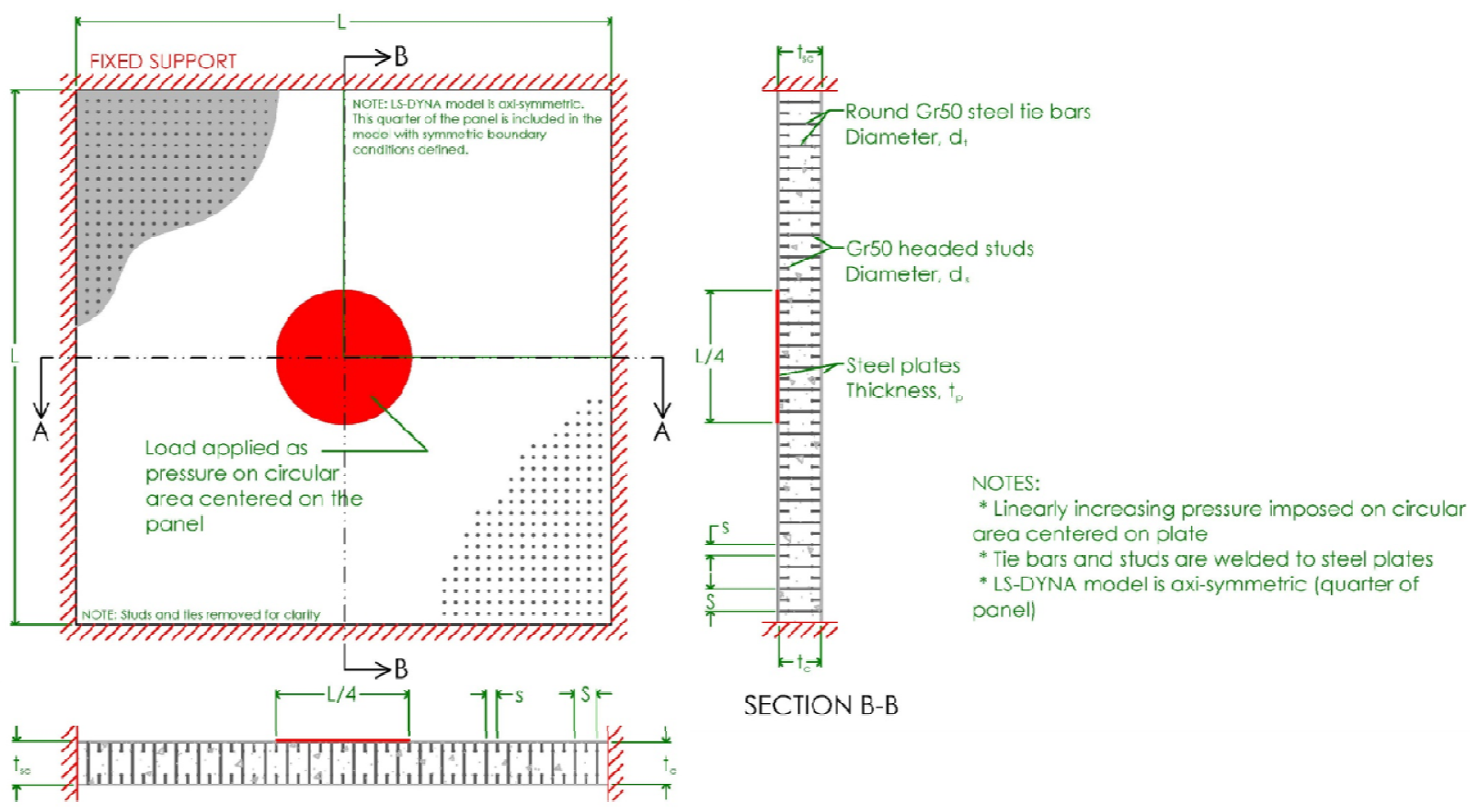

SECTION A-A

Figure 4: General Design of SC Panels for Parametric Study, after [25] 


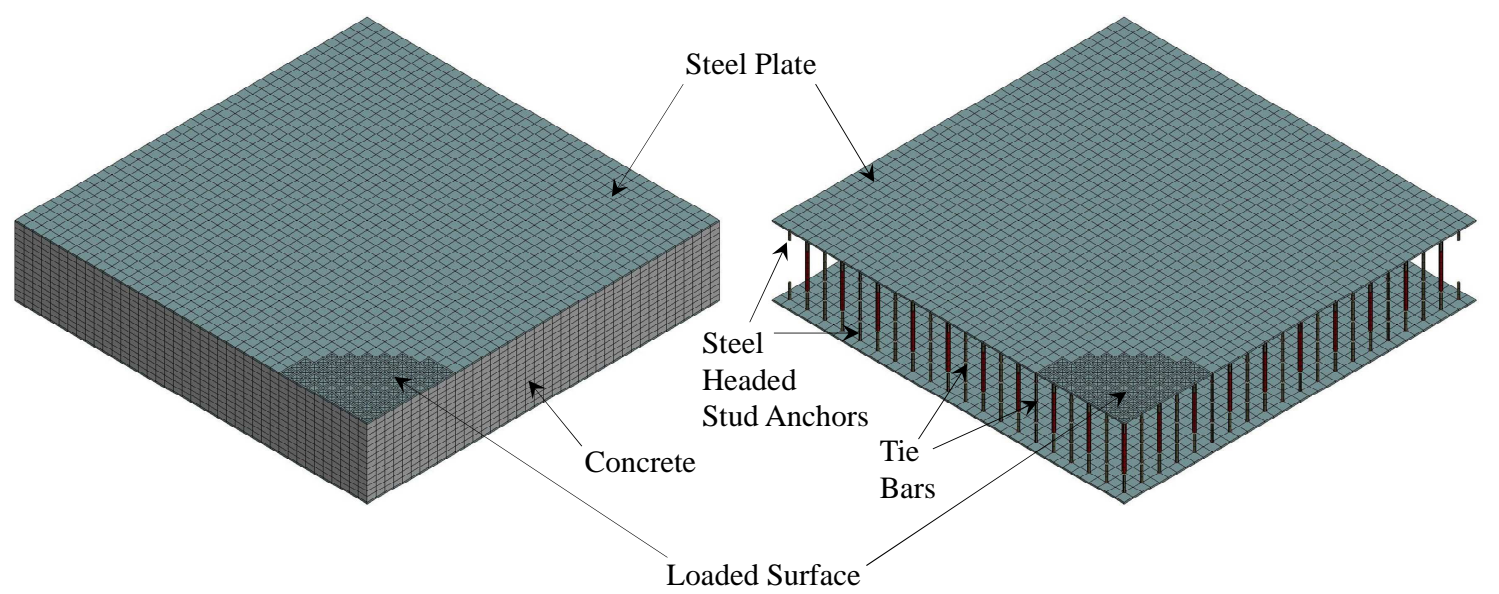

Figure 5: Typical SC Wall Finite Element Model, after [25]

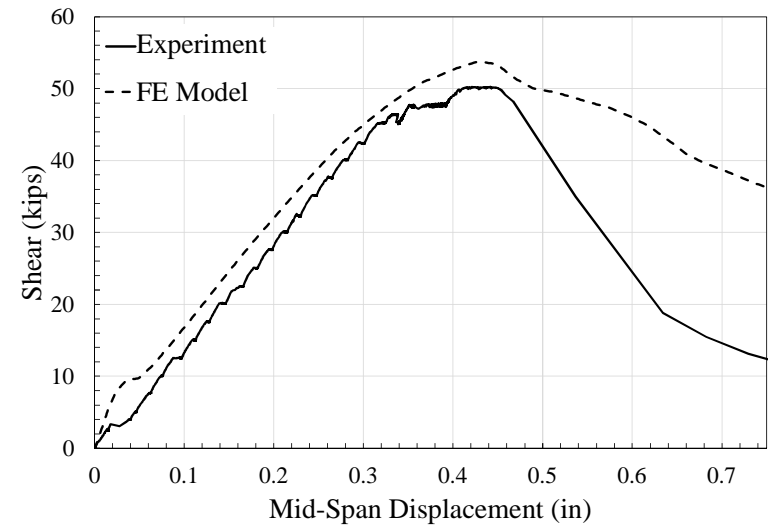

(a) SP1-3

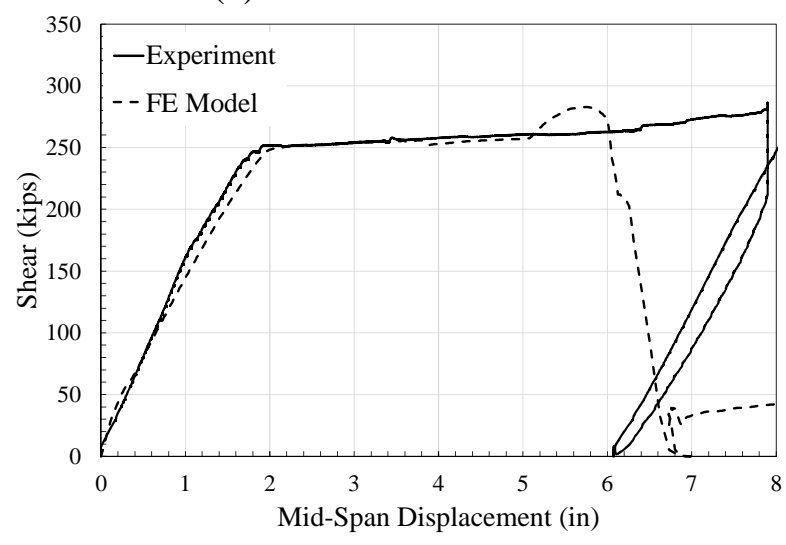

(c) SP2a-4

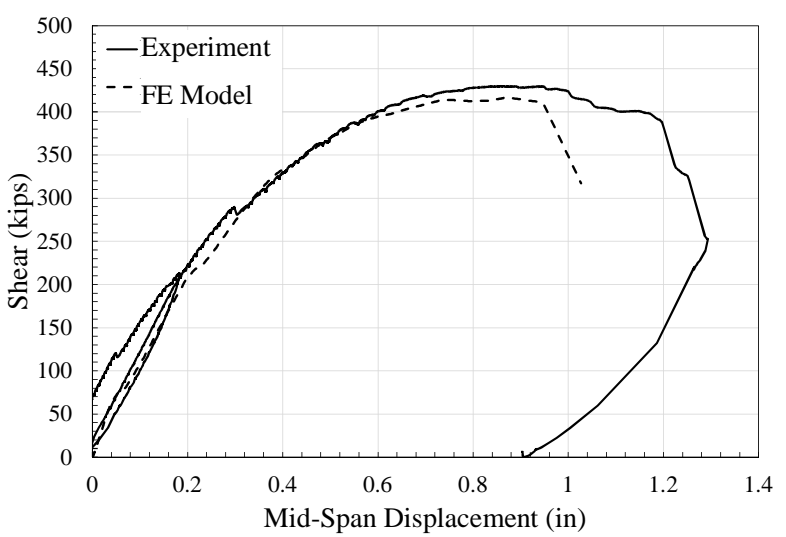

(b) SP2a-3

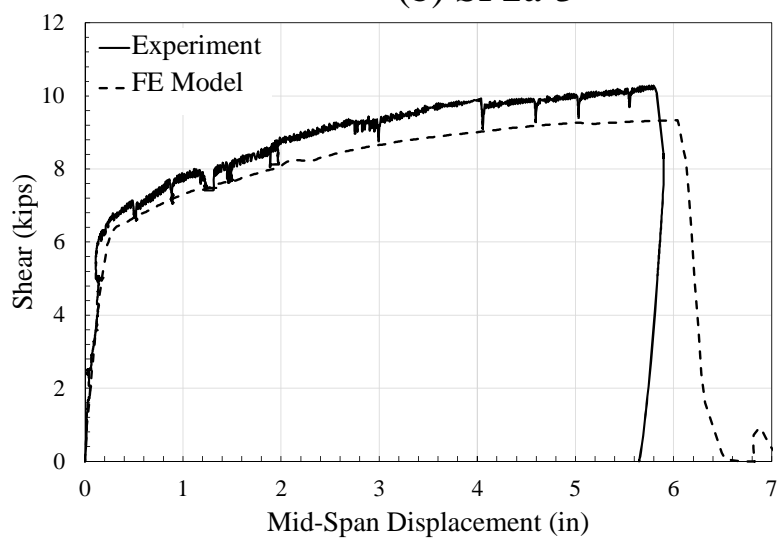

(d) S-1-A

Figure 6: Verification of Finite Element Modeling Approach (Representative Specimens) 


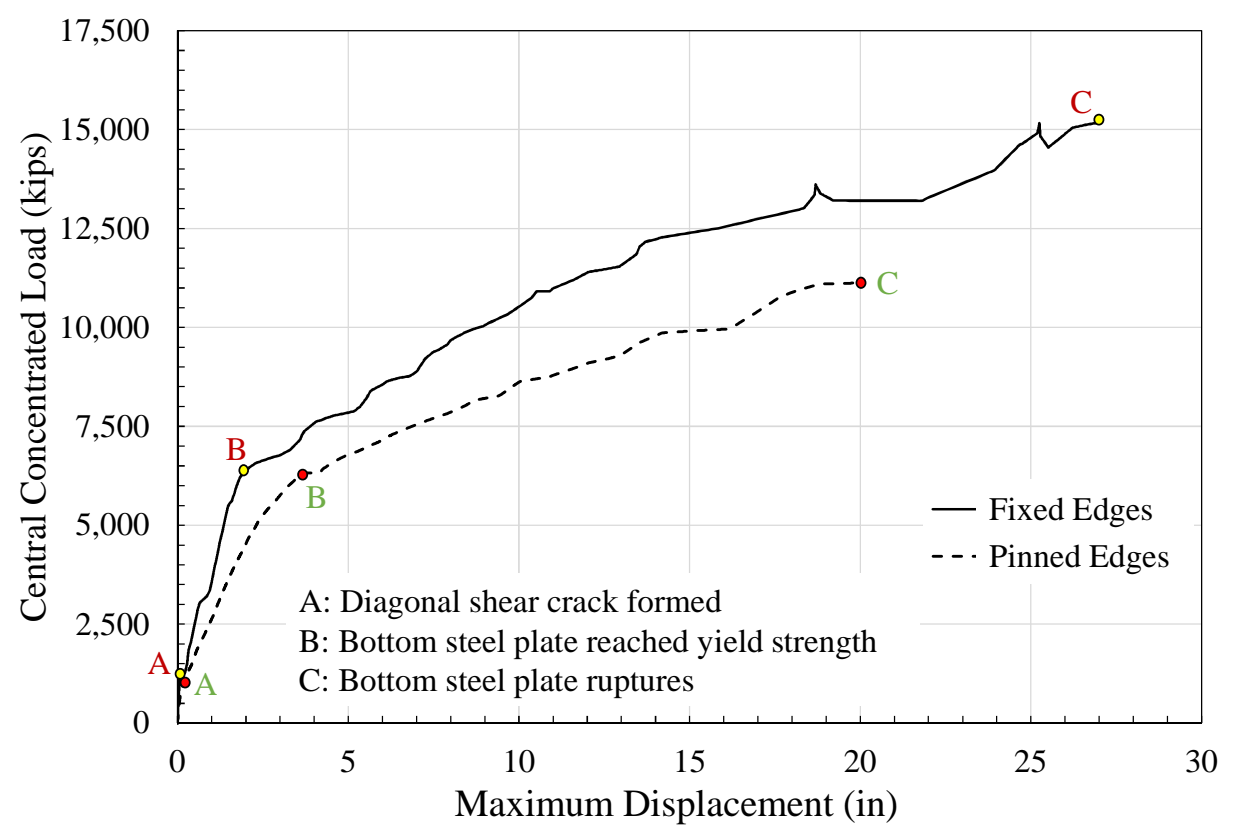

Figure 7: Representative Force-Displacement for Fixed Edges and Simply Supported Edges

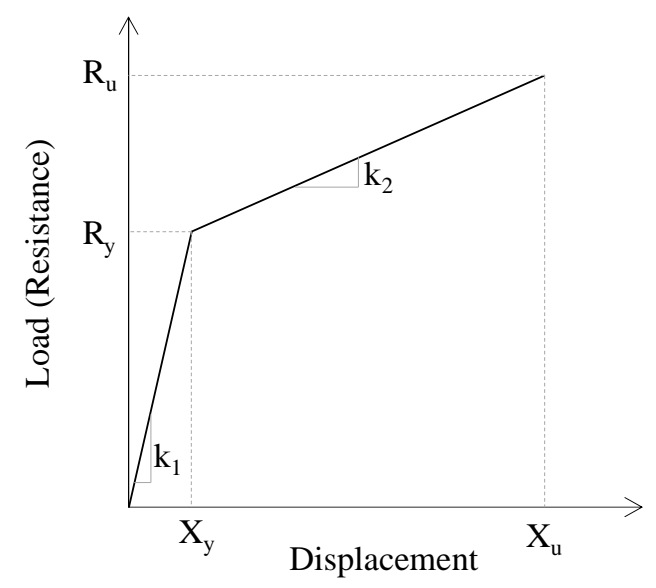

Figure 8: Idealized Resistance Function for SC Panels 


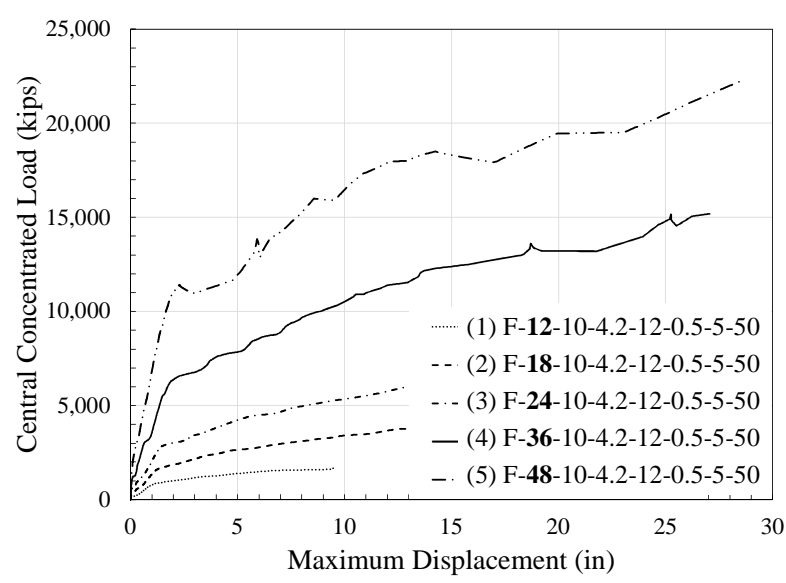

(a) $P$ - $\Delta$ responses

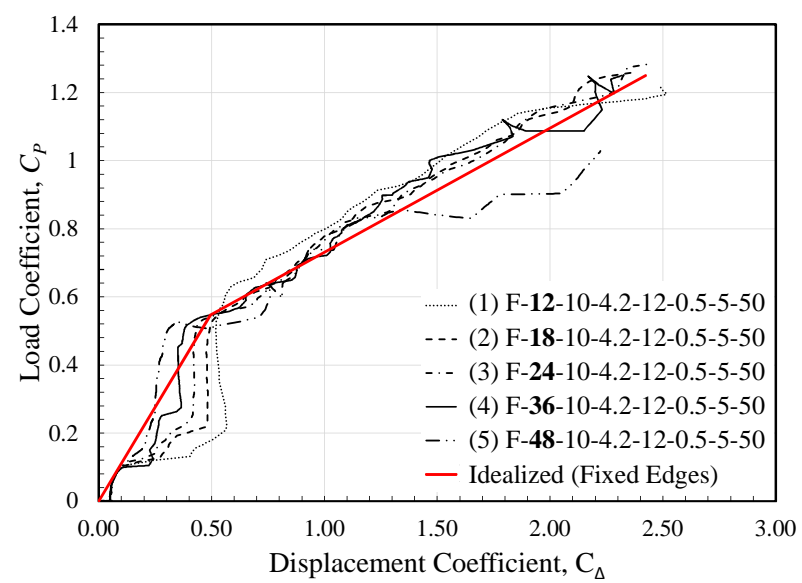

(b) $C_{P}-C_{\Delta}$ responses

Figure 9: Influence of $t_{s c}$ on Load-Displacement Behavior of SC Panels

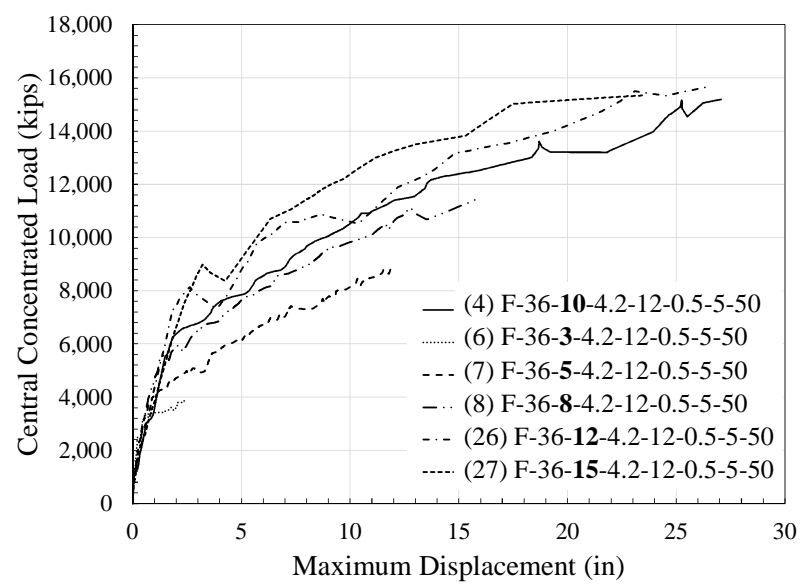

(a) $P$ - $\Delta$ responses

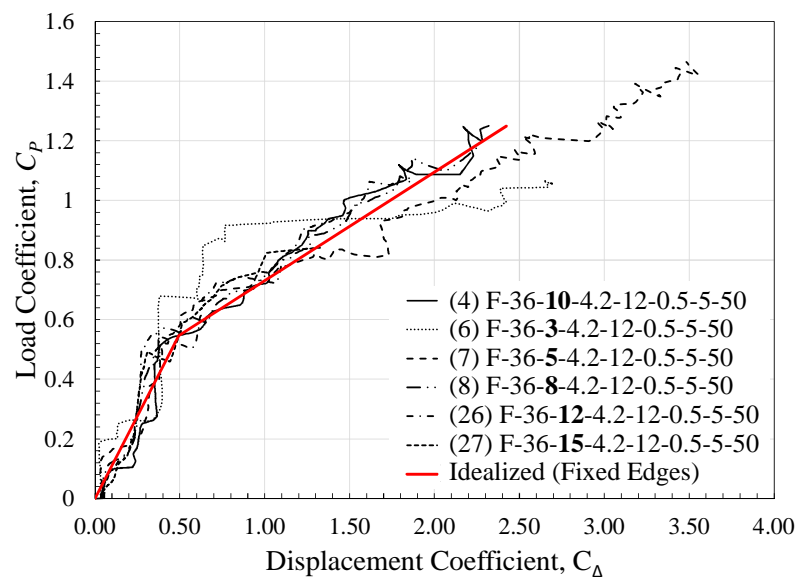

(b) $C_{P}-C_{\Delta}$ responses

Figure 10: Influence of $L / t_{s c}$ on Load-Displacement Behavior of SC Panels 


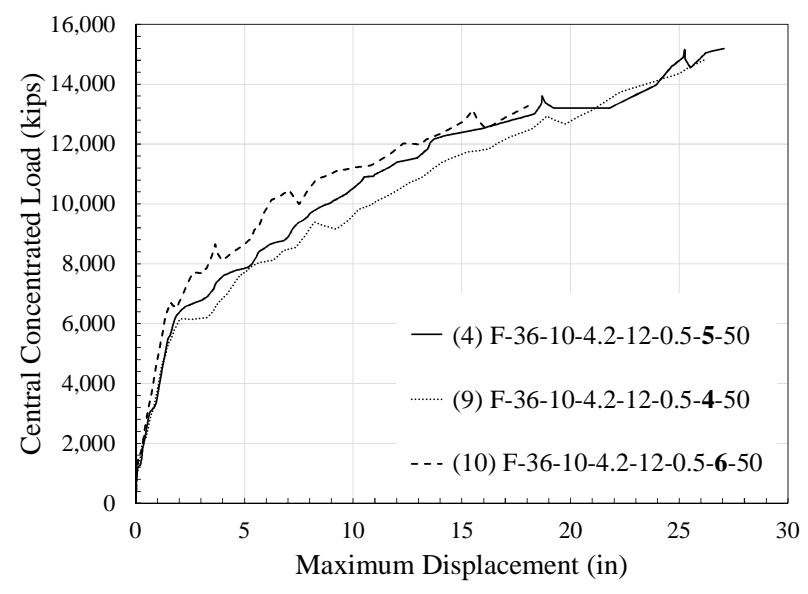

(a) $P-\Delta$ responses

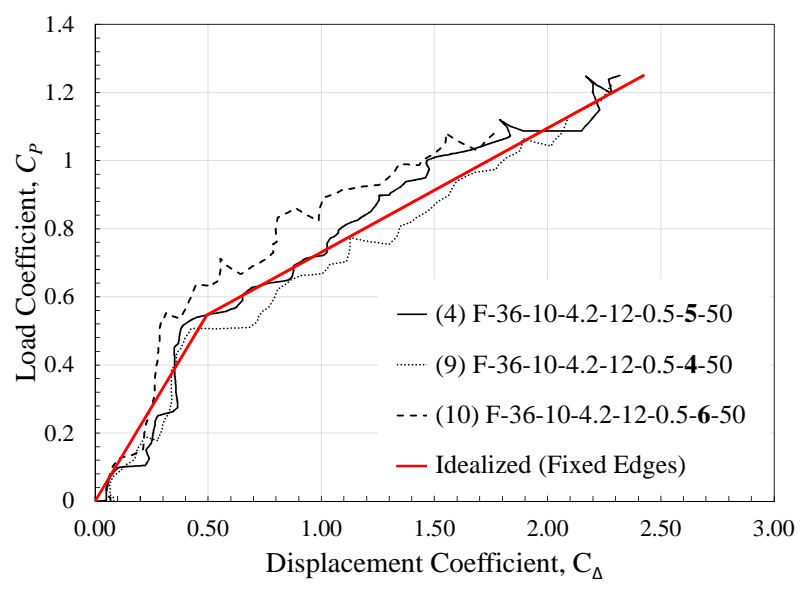

(b) $C_{P^{-}} C_{\Delta}$ responses

Figure 11: Influence of $f^{\prime}{ }_{c}$ on Load-Displacement Behavior of SC Panels

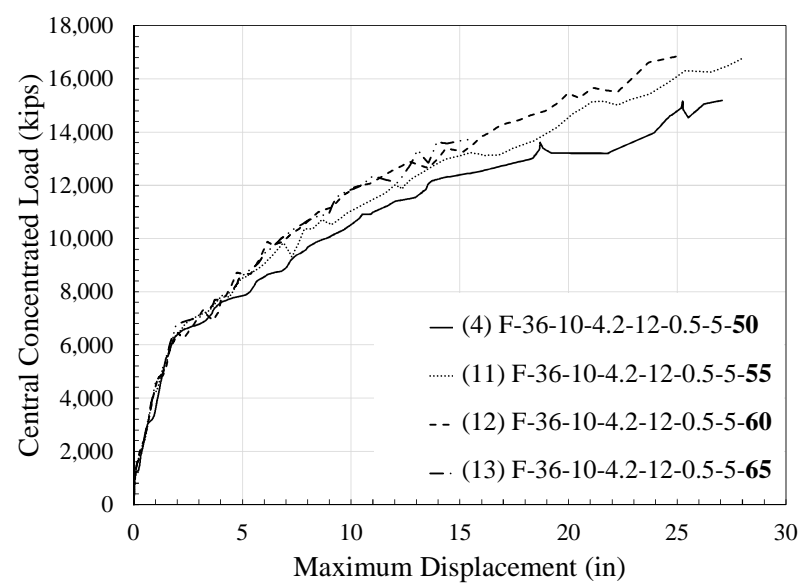

(a) $P-\Delta$ responses

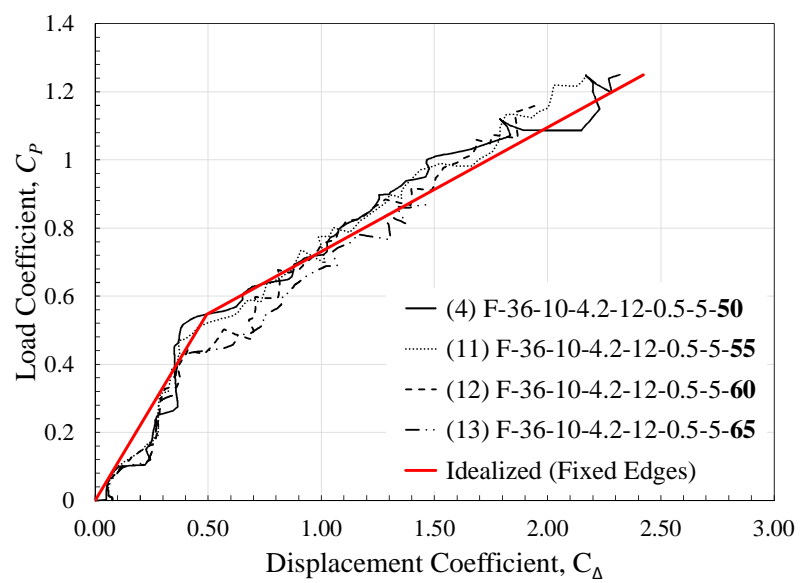

(b) $C_{P}-C_{\Delta}$ responses

Figure 12: Influence of $F_{y}$ on Load-Displacement Behavior of SC Panels 


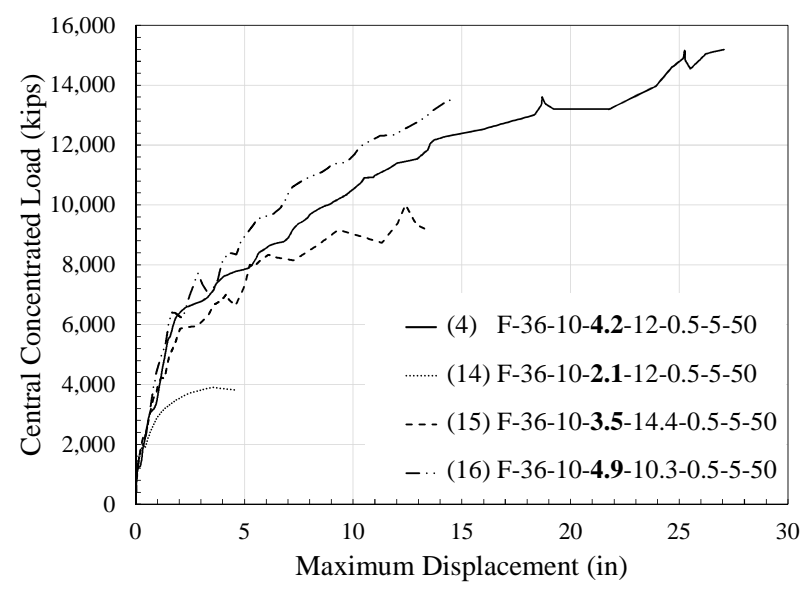

(a) $P$ - $\Delta$ responses

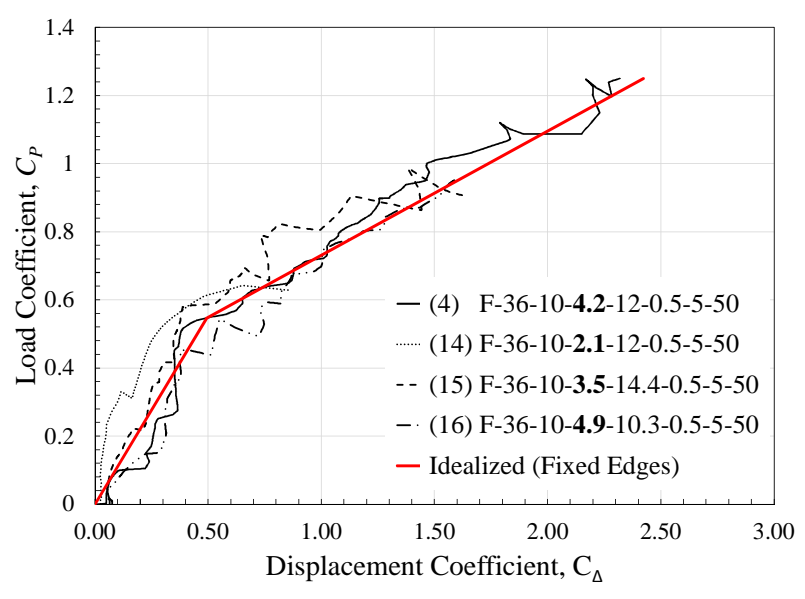

(b) $C_{P}-C_{\Delta}$ responses

Figure 13: Influence of $\rho$ on Load-Displacement Behavior of SC Panels

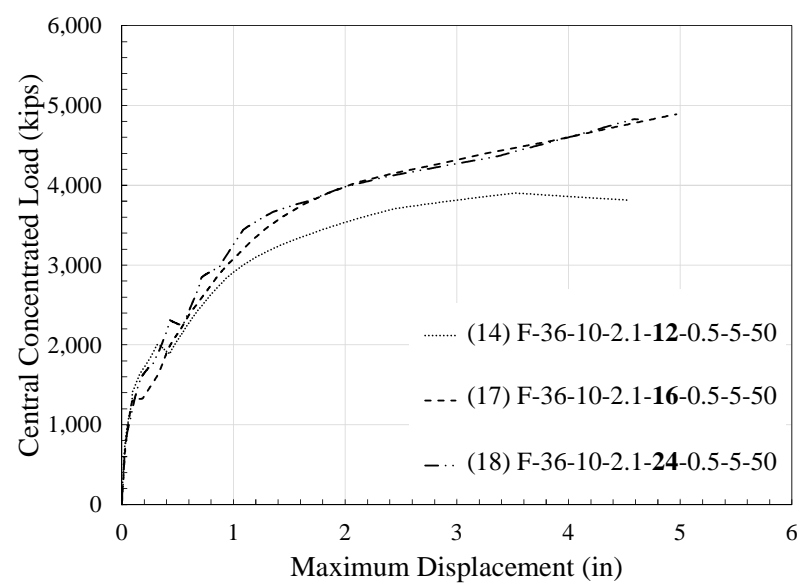

(a) $P$ - $\Delta$ responses

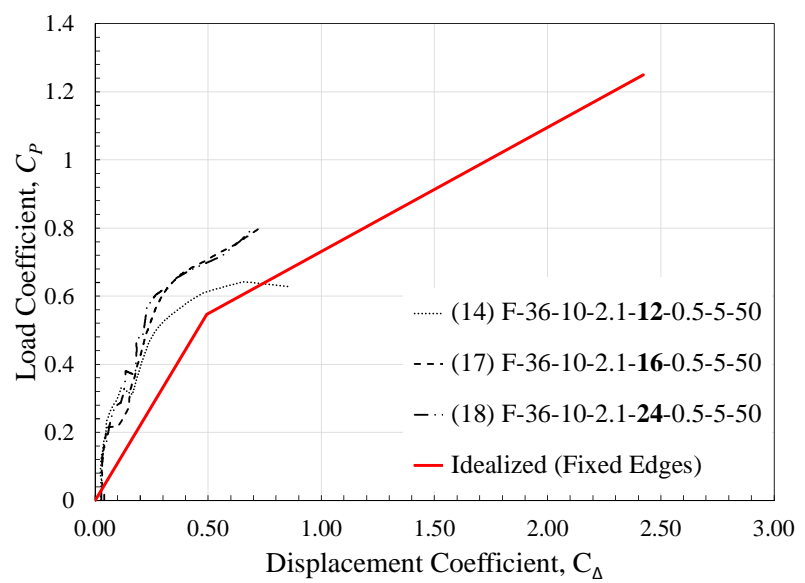

(b) $C_{P}-C_{\Delta}$ responses

Figure 14: Influence of $s / t_{p}$ on Load-Displacement Behavior of SC Panels 


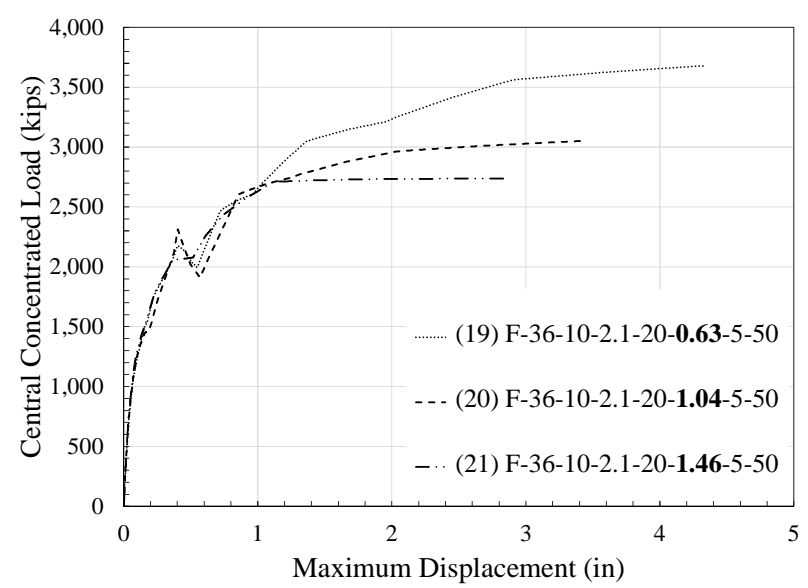

(a) $P$ - $\Delta$ responses

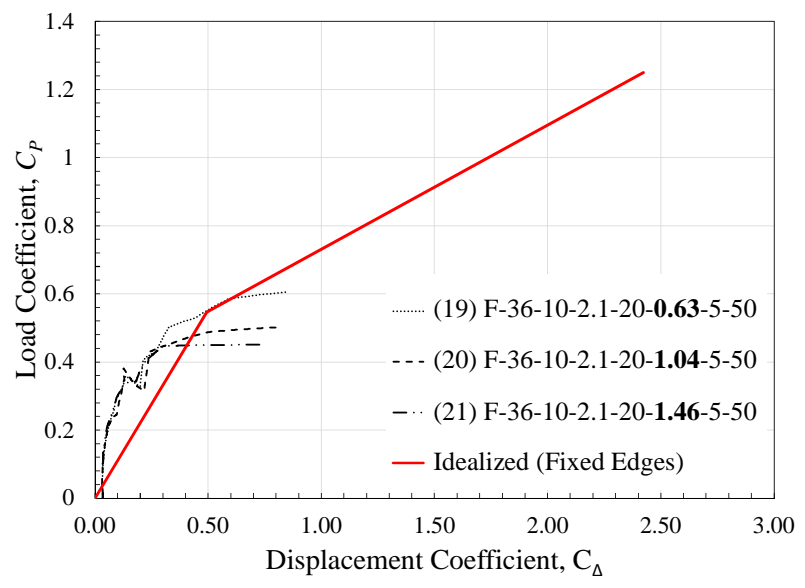

(b) $C_{P}-C_{\Delta}$ responses

Figure 15: Influence of $S / t_{s c}$ on Load-Displacement Behavior of SC Panels

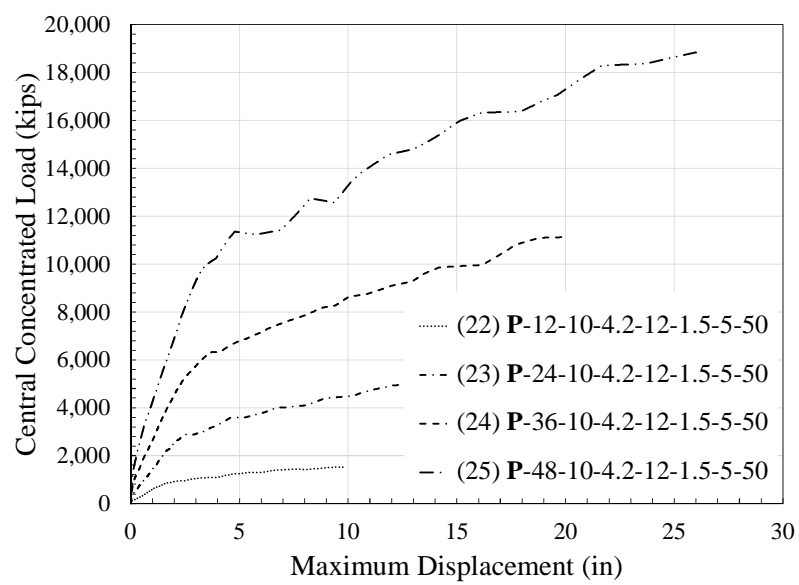

(a) $P$ - $\Delta$ responses

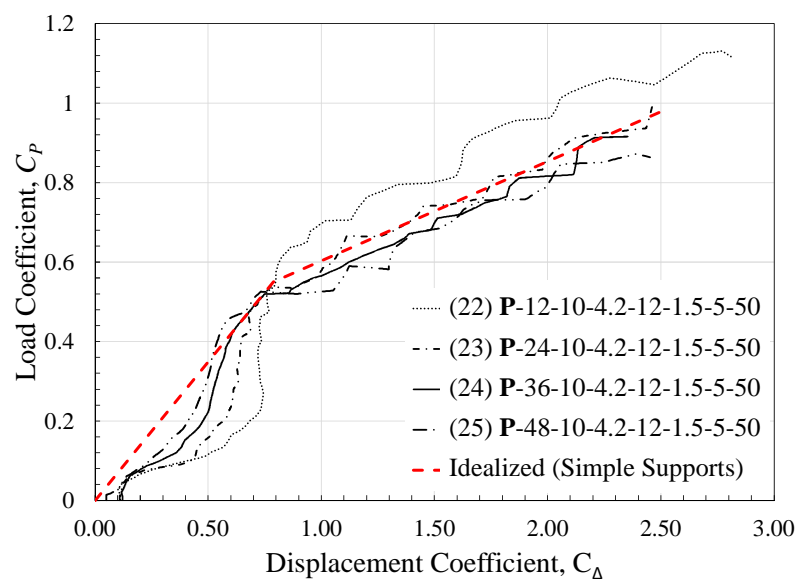

(b) $C_{P^{-}} C_{\Delta}$ responses

Figure 16: Influence of Support Conditions on Load-Displacement Behavior of SC Panels 